\title{
O MAGMATISMO GRANÍTICO NEOPROTEROZÓICO DO BATÓLITO PELOTAS NO SUL DO BRASIL: NOVOS DADOS E REVISÃO DA GEOCRONOLOGIA REGIONAL
}

\author{
RUY PAULO PHILIPP', RÔMULO MACHADO ${ }^{2}$, LAURO VALENTIN STOLL NARDI ${ }^{1} \&$ \\ JEAN MICHEL LAFON ${ }^{3}$
}

\begin{abstract}
THE NEOPROTEROZOIC GRANITICMAGMATISM OF THE PELOTAS BATOLITH IN SOUTH BRAZIL: NEW DATA AND REVIEW OF THE REGIONAL GEOCHRONOLOGY The Pelotas Batholith is an about 40,000 $\mathrm{km}^{2}$ polyphase plutonic complex located in the eastern part of Sul-rio-grandense Shield, southernmost Brazil. It is composed of six granitic suites (Pinheiro Machado, Erval, Viamão, Encruzilhada do Sul, Cordilheira and Dom Feliciano) and one syenitic suite (Piquiri). The batholith shows a compositional evolution from suites dominated by granodiorites and monzogranites with minor tonalites, diorites, and quartz-diorites to those dominated by syenogranites with microcline-ortoclase granites, quartz-syenites, and subordinated syenites. All the suites contain basic and intermediate rocks with mixing and mingling relations indicating they are coeval with the granitic magmatism. The Pinheiro Machado Suite has a medium to high-K nature and ages from $625 \mathrm{Ma}$ to $610 \mathrm{Ma}$ and the Viamão Suite shows high-K calc-alkaline affinity and ages about $600 \mathrm{Ma}$. The Cordilheira Suite is more peraluminous then the former: The Piquirí Suite resulted from an alkaline satured shoshonitic magmatism at about $610 \mathrm{Ma}$. Metaluminous and peralkaline alkaline supersatured rocks form the Encruzilhada do Sul Suite, with ages between $600 \mathrm{Ma}$ and $590 \mathrm{Ma}$, and in granite and rhyolite dikes included in the Don Feliciano Suite, of $595 \mathrm{Ma}$ to $570 \mathrm{Ma}$. Basement megaxenoliths are widespread in these suites and are similar to the metamorphic rocks found at the western border of this batholith. The Pelotas Batholith contains evidence of two ductile deformational events ( $D$ and $\mathrm{D}_{2}$ ) and one ruptile $\left(\mathrm{D}_{3}\right)$. Most suites were emplaced in a transpressive regime, during a post-collisional stage, being partially accompanied by oblique convergence and transcurrence of continental plates. Available geocronological data indicate that $D_{1}$ and $D_{2}$ have similar age and that the Pelotas Batholith magmatism has ages from $630 \mathrm{Ma}$ to $570 \mathrm{Ma}$. Granitic magmatism of the batholith shows an important mantle contribution represented by diorites associated to most of the studied suites, which are part of a mafic magmatism The generation and emplacement of the granitic magmatism are related to the evolution of the ductile shear zones. These structures have also influenced the occurrence of mafic magmatism that contributed to increase the geothermal gradients and to promote crustal melting and the generation of granitic rocks in the batholith.
\end{abstract}

Keyworls: Sul-rio-grandense Shield, Pelotas Batholith, geochronology, petrology, granitoids

RESUMO O Batólito Pelotas é um complexo plutônico multi-intrusivo e polifásico com cerca de $40.000 \mathrm{Km}^{2}$ e situado na porção leste do Escudo Sul-Rio-Grandense. O batólito é composto por seis suítes graníticas (Pinheiro Machado, Erval, Viamão, Encruzilhada do Sul, Cordilheira e Dom Feliciano) e uma sienítica (Suíte Piquiri). O magmatismo que formou o batólito mostra evolução composicional caracterizada inicialmente por granodioritos e monzo-granitos, com tonalitos, dioritos e quartzo diorito subordinados, que gradam para suítes dominadas por sienogranitos, com raros microclínio-ortoclásio granitos, quartzo-sienitos e sienitos. Todas as suítes apresentam associação com rochas básicas a intermediárias e apresentam relações de mistura homogênea e heterogênea com os magmas graníticos. A Suíte Pinheiro Machado é cálcio-alcalina médio a alto-K, metaluminosa a levemente peraluminosa, com idade entre 625 a $610 \mathrm{Ma}$ e a Suíte viamão é cálcio-alcalina alto-K e de idade em torno de $600 \mathrm{Ma}$. A Suíte Cordilheira é cálcioalcalina e peraluminosa. A Suíte Piquirí é alcalina saturada de afinidade shoshonítica e de idade em torno de 610 Ma. Manifestações de natureza alcalina supersaturada metaluminosa e peralcalina são representadas pelos granitos da Suíte Encruzilhada do Sul, de idade em torno de 600 a $590 \mathrm{Ma}$ e, por alguns corpos graníticos e diques de riolito, ambos pertencentes a Suíte Dom Feliciano, a qual tem continuidade até o final da evolução do batólito, entre 595 e $570 \mathrm{Ma}$. Septos do embasamento estão presentes em todas as suítes, sugerindo ampla simelhança com as rochas encaixantes encontradas a oeste do batólito. O batólito contém evidências de três eventos deformacionais, dois dos quais $\left(D_{1}\right.$ e $\left.D_{2}\right)$ dúteis e um $\left(D_{3}\right)$ rúptil. A colocação da maioria das suítes ocorreu em regime transpressivo, durante estágio pós-colisional, sendo em parte acompanhada por fase de convergência oblíqua e transcorrência de placas continentais. A semelhança das idades obtidas para a movimentação das zonas de cisalhamento oblíquas e transcorrentes de $D_{1}$ e $D_{2}$ é indicativa da sua contemporaneidade. As idades disponíveis, obtidas a partir de diversos métodos geocronológicos, indicam consistentemente um período entre 630 e 570 Ma para a evolução geológica do Batólito Pelotas. O magmatismo teve contribuição mantélica representada por dioritos associados à maioria das suítes graníticas. A geração e colocação do magmatismo granítico estão relacionadas principalmente com a evolução de zonas de cisalhamento transcorrentes dúcteis. Estas estruturas influíram na formação do magmatismo máfico, que contribui para a elevação do gradiente termal regional criando as condições necessárias para a fusão crustal e geração das rochas graníticas do batólito.

Palavras-chaves: Escudo Sul-rio-grandense, Batólito Pelotas, geocronologia, petrologia, granitóides

1 - Centro de Estudos em Petrologia e Geoquímica, Instituto de Geociências-UFRGS. Av. Bento Gonçalves, 9500, Porto Alegre - RS. Caixal Postal 15001, CEP - 91540.000, e-mail: ruy.philipp@ufrgs.br; lauro.nardi@ufrgs.br.

2- Instituto de Geociências, USP, Pesquisador do CNPq, Rua do Lago, 562, Cidade Universitária, CEP-05422-970, São Paulo, SP, e-mail: rmachado@usp.br: 3 - Laboratório de Geologia Isotópica, Pará-Iso, Universidade Federal do Pará, PA, e-mail: lafonjm@ @ufpa.br 
INTRODUÇÃO O Batólito Pelotas, situado na porção leste do Escudo Sul-Rio-Grandense, tem cerca de $400 \mathrm{~km}$ de comprimento e entre $80 \mathrm{~km}$ e $120 \mathrm{~km}$ de largura. Tem continuidade para norte, em Santa Catarina, e, para sul, no Uruguai, como mostram os levantamentos geológicos e geofísicos (Shukowsky et al. 1991, Hallinan et al. 1993. Bitencourt \& Nardi 2000) (Fig. 1). O batólito é um complexo plutônico composto de várias suítes, cujo magmatismo teve duração de cerca de $70 \mathrm{Ma}$ (entre $630 \mathrm{Ma}$ e $570 \mathrm{Ma}$ ). A formação do batólito resulta da adição de distintos processos tectônicos durante o Ciclo Brasili-ano/Pan-africano e se postulam para a mesma modelos que envolvem a subducção de litosfera ocêanica em margem continental espessa (Figueiredo et al. 1990, Philipp 1990, Fragoso Cesar 1991, Philipp et al. 1993, Philipp 1998, Chemale Jr. 2000), colisão continental (Hartmann et al. 2000, Philipp \& Machado 2001) e reativação de fontes mantélicas modificadas em períodos tardi a pós-colisional (Bitencourt \& Nardi 1993, 2000). Chemale Jr. (2000) relaciona à orogênese Dom Feliciano, estágio final do Ciclo Brasiliano.

No batólito foram caracterizadas seis suítes graníticas denomi-nadas de Pinheiro Machado, Erval, Viamão, Encruzilhada do Sul, Corditheira, Dom Feliciano e uma sienítica, a Suíte Piquiri (Philipp 1998, Philipp \& Machado 2001) (Fig. 2). Nestas suítes, constituídas essencialmente por rochas graníticas, comumente ocorrem corpos básicos e enclaves máficos microgranulares, os quais apresentam relações de contato indicativas de mistura química e física com os líquidos de composição granítica. Os corpos básicos mais expressivos ocorrem nas imediações das cidades de Pinheiro Machado e Dom Feliciano, tendo sido descritos como Gabros Passo da Fabiana (Fragoso Cesar 1991) e o Diorito Capim Branco (Wildner \& Ramgrab 1994). As rochas básicas têm sido descritas como associadas geneticamente com as suítes Viamão e Dom Feliciano.

Em todas as suítes graníticas ocorrem septos do embasamento, representados por rochas metamórficas de baixo a alto grau (Fragoso Cesar et al. 1986, Philipp 1990, 1998, Philipp \& Ma-chado 2002a).

A Suíte Pinheiro Machado é cálcio-alcalina, médio a alto-K, metaluminosa a fracamente peraluminosa. As Suítes Viamão e Cordilheira têm afinidade cálcio-alcalina alto-K, mas diferem entre si pelo caráter metaluminoso a fracamente peraluminoso da primeira e peraluminoso da última. Os sienitos da Suíte Piquirí têm afinidade shoshonítica, enquanto os granitos da Suíte Encruzilhada do Sul são alcalinos e metaluminosos. Na sua ampla maioria, os corpos graníticos da Suíte Dom Feliciano são cálcio-alcalinos alto-K, com elevado grau de diferenciação ( $\mathrm{SiO}$ entre 75 e $78 \%$ ). São registradas nesta suíte rochas com tendência alcalina metaluminosa e peralcalina, representadas respectivamente por diques riolíticos e pelo Granito Bela Vista (Philipp et al. 1991).

Neste trabalho são apresentadas novas dados geocronológicos de granitos e sienitos do Batólito Pelotas, obtidas pelo método de evaporação do $\mathrm{Pb}$ de monocristais de zircão (TIMS). As idades foram realizadas no Laboratório de Geologia Isotópica (Pará-Iso) da Universidade Federal do Pará. Foram estudadas amostras das suítes Pinheiro Machado (granodiorito), Piqurirí (Sienitos Piquiri e Arroio do Silva), Viamão (Granito Chasqueiro) e Dom Feliciano (Granitos Capão do Leão e Bela Vista).

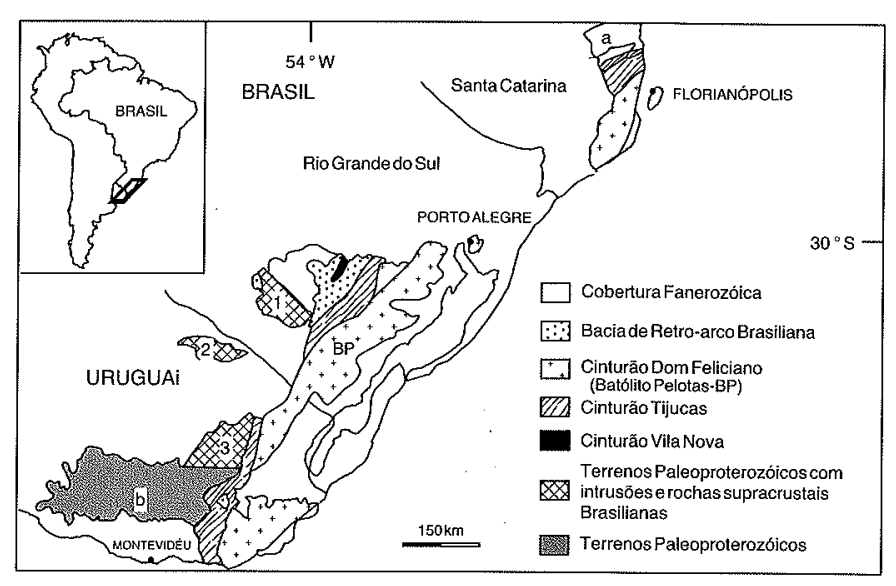

Figura 1 - Principais unidades geotectônicas do Sul do Brasil e Uruguai. Legenda: $a=$ Terreno Luis Alves, $b=$ Terreno Florida, $1=$ Terreno Taquarembó, $2=$ Terreno Rivera, $3=$ Terreno Valentines. Modificado de Chemale Jr: (2000).

ESTRUTURA DO BATÓLITO No batólito têm sido descritos três eventos deformacionais: dois mais antigos de natureza dúctil $\left(D_{1}\right.$ e $\left.D_{2}\right)$ e um mais novo, rúptil $\left(D_{3}\right)$. A colocação da Suíte Pinheiro Machado é relacionada ao evento $\mathrm{D}_{1}$, ocorrida em regime transpressivo durante o evento $\mathrm{D}_{1}$, que provavelmente representa os estágios tardios da colisão oblíqua Brasiliana (Philipp \& Machado 2001). Este evento é responsável pela formação de zonas de cisalhamento dúcteis de orientação $N 45^{\circ}-60^{\circ} \mathrm{E}$, e mergulhos de médio a baixo ângulo para NW. As zonas de cisalhamento são oblíquas, com lineação de estiramento mineral orientada segundo $\mathrm{E}-\mathrm{W}$ e indicadores cinemáticos (foliação SC, estiramento assimétrico de enclaves microgranulares) que mostram movimentos de topo para leste. Ao evento $\left(D_{2}\right)$ é atribuído à formação de zonas de cisalhamento dúcteis a dúctil-rúpteis de alto ângulo de mergulho. São estruturas com orientação $N 60^{\circ}-85^{\circ} \mathrm{E}$, que contêm lineação de estiramento suborizontal, cujos indicadores cinemáticos (foliação S-C, porfiroclastos assimétricos e discretas bandas de cisalhamentos) são compatíveis com.movimentação sinistral. Os posicionamentos dos maciços graníticos das demais suítes do batólito estão intimamente relacionados com o desenvolvimento destas zonas. Os corpos graníticos das suítes Viamão e Cordilheira são alongadas e concordantes com as zonas de cisalhamento transcorrentes, sendo comum à presença de estruturas magmáticas e tectônicas subparalelas as mesmas (Frantz \& Remus 1986, Gomes 1990, Philipp 1990, Philipp et al. 1993, Fernandes et al. 1990, 1993, Koester 1995). O evento defor-macional $\left(D_{3}\right)$, atribuído á reativação de zonas de cisalhamento do evento anterior, é de nível crustal mais raso e de condições extensionais. Estas zonas de cisalhamento, com Iargura métrica a decamétrica e subverticais, têm orientação $\mathrm{N} 20^{\circ} \mathrm{E}$ a $\mathrm{N} 50^{\circ}-65^{\circ} \mathrm{E}$ e deslocam as estruturas $\mathrm{D}_{2}$. Estas estruturas são materalizadas por milonitos de baixa temperatura. Os indicadores cinemáticos destas zonas (bandas de cisalhamento discretas e estrias de atrito), juntamente com uma lineação de 


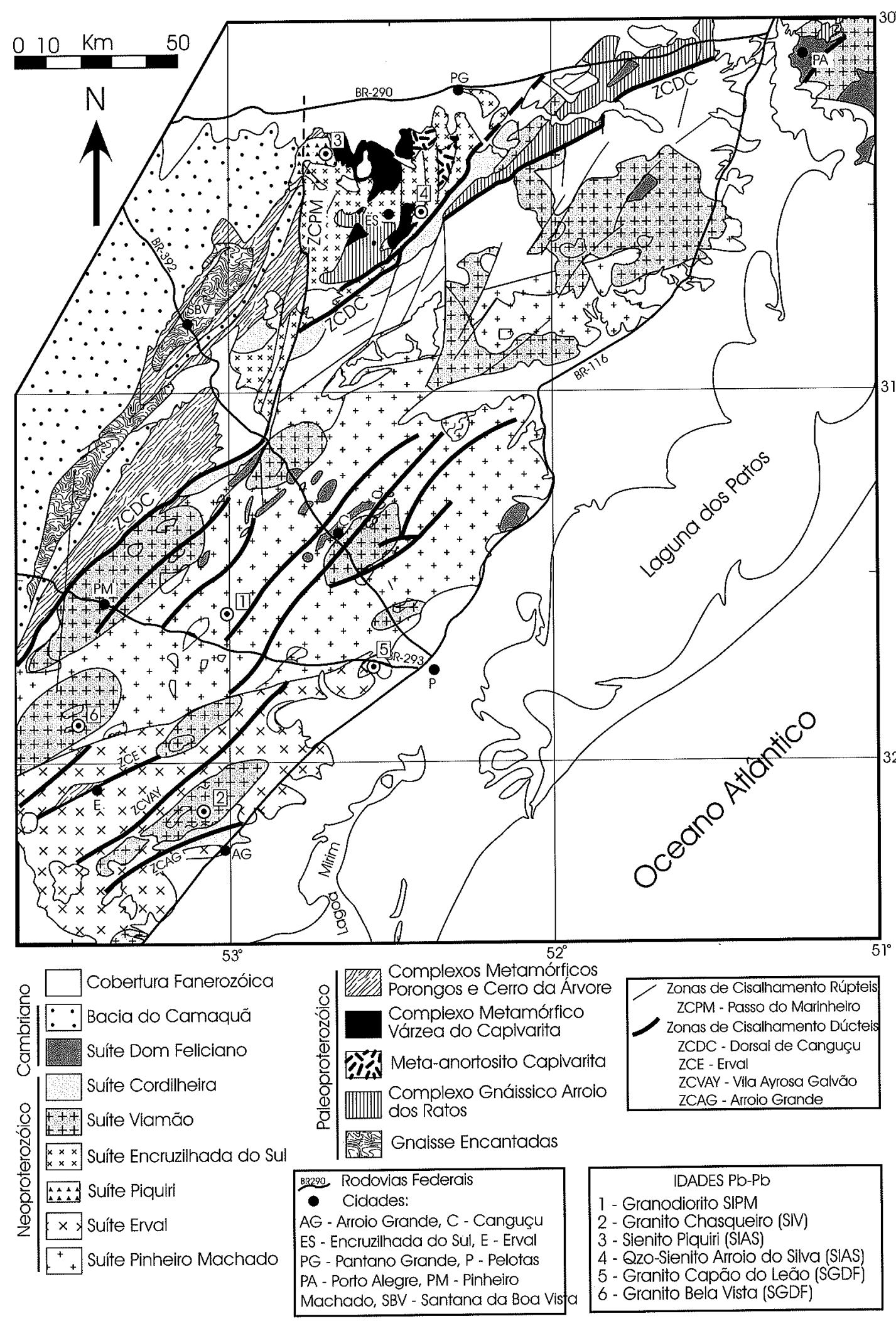

Figura 2-Mapa geológico do Batólito Pelotas mostrando a distribuição das suítes graníticas, das principais zonas de cisalhamento transcorrente e a localização aproximada das amostras selecionadas para os estudos geocronológicos. 
estiramento mineral sub-horizontal, sugerem deslocamento direcional sinistral. Este novo sistema é responsável pela ascensão e posicionamento dos granitos da Suíte Dom Feliciano, os quais são alongados e concordantes com as zonas, com a deformação restrita à borda de alguns maciços.

Os dados isotópicos disponíveis sobre o Batólito Pelotas indicam que o magmatismo durou por cerca de $80 \mathrm{Ma}$, entre 630 e $550 \mathrm{Ma}$, sugerindo que na sua constituição houve participação de fontes crustais e mantélicas.

\section{DESCRIÇÃO DAS UNIDADES ESTUDADAS Suíte} Pinheiro Machado Esta suíte ocupa faixa alongada na direção NE-SW na porção central do Batólito Pelotas e perfaz cerca de $30 \%$ de sua área (Fig. 2). É a suíte mais antiga do batólito. Caracteriza-se pela presença de foliação de baixo ângulo atribuída ao evento deformacional $\mathrm{D}_{1}$. Possui composição expandida, de granodiorítica a monzogranitíca, com tonalitos, dioritos e quartzo-dioritos subordinados. Estas rochas apresentam cor cinza, textura equigranular hipidiomórfica média a grossa, localmente inequigranular, com pequenas proporções de fenocristais (1 a $3 \mathrm{~cm}$ ) esparsos de feldspato potássico. O plagioclásio é cucdral, branco; o quartzo é amebóide; a biotita é euedral e ocorre em agregados intersticiais. O feldspato potássico é ortoclásio, subordinado e intersticial. Os minerais acessórios compreendem zircão, allanita, apatita, titanita e minerais opacos. Esta suíte exibe evidências de mistura homogênea e heterogênea entre os líquidos graníticos e os líquidos máficos geradores de enclaves microgranulares de composição diorítica, quartzo-diorítica e tonalítica. Os enclaves são centimétricos, arredondados a subarredondados. Os seus contatos com as rochas granitóides encaixantes são definidos por limites curvos a lobados. São encontrados nesta suíte diversos septos do embasamento, constuídos por ortognaisses e metagranitos miloníticos, anfibolitos, gnaisses calci-silicáticos e aluminosos. As rochas da Suíte Pinheiro Machado ocorrem como xenólitos em rochas das suítes Erval, Viamão, Cordilheira e Dom Feliciano. Foram analisados desta suíte os zircões de uma amostra de granodiorito oriunda de pedreira situada nas margens da rodovia de Pelotas a Pinheiro Machado (BR 153), junto à ponte do rio Piratini (coordenadas UTM: N-6490101 e E-0320103).

Suíte Viamão Os granitos desta suíte afloram em diferentes porções do Batólito Pelotas, e ocupam área de cerca de $15 \%$ do mesmo. Constituem corpos alongados na direção $N 40^{\circ}-50^{\circ} \mathrm{E}$, com $25 \mathrm{~km}$ a $40 \mathrm{~km}$ de comprimento e entre $5 \mathrm{~km} \mathrm{e} 15 \mathrm{~km}$ de largura. A colocação dos maciços desta suíte está associada à movimentação das zonas de cisalhamento de alto ângulo $\mathrm{D}_{2} . \mathrm{A}$ variação composicional é dominada por monzogranitos, com granodioritos e sienogranitos subordinados. A textura é porfirítica a heterogranular grossa, com foliação magmática definida pelo alinhamento de fenocristais de feldspato potássico e lamelas de biotita. Esta estrutura é concordante com a foliação milonítica das zonas de cisalhamento de alto ângulo, o que posiciona estes granitos como sin- a tardi- $\mathrm{D}_{2}$. A maioria dos corpos estudados exibe estruturas indicativas de mistura heterogênea e homogênea de magmas, com diversos graus de hibridização, envolvendo termos de composição básica a intermediária e ácida. Ocorrem enclaves microgranulares, centimétricos a métricos, por vezes decamétricos, de compo- sição diorítica, em contato gradacional com os granitos onde ocorrem e desenvolvem zonas métricas de termos híbridos (Philipp 1998). Também ocorrem xenólitos de metagranitóide e ortognaisse com evidências de reduzido grau de assimilação pelo material granítico. Maiores graus de interação com os magmas graníticos foram observados apenas nos xenólitos de pequenas dimensões, com a formação de estruturas fantasmas e bandamento irregular com schlieren de biotita.

GRANITO CHASQUEIRO O Granito Chasqueiro tem cerca de $400 \mathrm{~km}^{2}(40 \times 10 \mathrm{~km})$, ocorre a noroeste da cidade de Arroio Grande e, em planta, é alongado segundo N50E (Fig. 2). É cinza claro e tem composição monzogranítica a sienogranítica, textura porfirítica a heterogranular grossa com fenocristais de ortoclásio em matriz equigranular, hipidiomórfica grossa (5 a $8 \mathrm{~mm}$ ), composta por quartzo, microclínio, plagioclásio, biotita e rara hornblenda. Os fenocristais atingem proporções modais entre 35 a $50 \%$ e variam entre 2 e $6 \mathrm{~cm}$. O ortoclásio é prismático, subédrico a euédrico e é o principal mineral da rocha. $\mathrm{O}$ plagioclásio é raro, branco e prismático equidimensional. $\mathrm{O}$ quartzo é amebóide e incolor. A biotita ocorre em agregados intersticiais, os quais, junto com o anfibólio, marca a foliação da rocha. Os minerais acessórios compreendem zircão, apatita, allanita, titanita e opacos. Os enclaves máficos, quando presentes, são subarredondados, com dimensões entre 10 a $25 \mathrm{~cm}$.

Este granito apresenta foliação do tipo $S=L$ penetrativa, mais proeminente junto às zonas de cisalhamento. A foliação é anastomosada, de direção $\mathrm{N}^{\circ} 5^{\circ}-70^{\circ} \mathrm{E}$ e mergulhos subverticais. A porção central do corpo preserva foliação de fluxo magmático dada pela orientação da biotita e ortoclásio, a qual transiciona lateralmente para a foliação tectônica de borda, onde a textura é protomilonítica. A lineação mineral é dada pela orientação dos cristais de K-feldspato, orientados segundo NE-SW e com cai-mento entre $2^{\circ}$ a $30^{\circ}$. A amostra datada foi retirada de pedreira próximo a Arroio Grande, na RST-473 (Coordenadas UTM: N-6440353 e E-0297320).

Suíte Encruzilhada do Sul e Piquiri Os granitos da Suíte Encruzilhada do Sul são restritos à porção NW do batólito e perfazem cerca de $10 \%$ de sua área. A suíte é composta pelos granitos Encruzilhada do Sul, Pinheiros, Campinas e Pitangueiras. Os corpos dispõem-se em faixa alongada segundo $\mathrm{N} 40^{\circ} \mathrm{E}$, limitada a leste pela Zona de Cisalhamento Dorsal de Canguçu e a oeste pelo Complexo Metamórfico Cerro da Árvore. A Zona de Cisalhamento Passo do Marinheiro, de direção próxima a N-S, afeta estes granitos com intensa cataclase e fraturamento.

O Granito Encruzilhada do Sul é o corpo mais expressivo da suíte e contem duas fácies petrográficas principais: biotitagranitos porfiríticos a heterogranulares grossas, acinzentados a róseo-acinzentados ou alaranjados, e leucogranitos equigranulares, rosa e cinza-claros. A fácies porfirítica é dominante e composta por biotita-monzogranitos, subordinadamente biotita granodioritos e dioritos. Rochas da fácies porfirítica contém entre $15 \%$ e $40 \%$ de fenocristais euedrais de feldspato potássico em matriz equigranular hipidiomórfica constituída por plagioclásio euedral, agregados de biotita euedral e quartzo globular a prismático. Os acessórios compreendem anfibólio, zircão, apatita e minerais opacos. A fácies equigranular é homogênea e consiste de leucossienogranitos cortados por corpos 
pegmatóides e diques de aplito. A Suíte Encruzilhada do Sul contém zonas com abundância de enclaves máficos (diorito e quartzo-diorito) microgranulares e zonas híbridas, nas quais são comuns feições de interação entre o líquido félsico e os corpos intermediários a básicos, resultando em estruturas de mistura heterogênea de magmas e zonas de hibridização (Bitencourt et al. 1993, Vasquez 1997). Os Sienitos Piquiri e Arroio do Silva, anteriormente incluídos na Suíte Encruzilhada do Sul por Vasquez (1997), representam evento magmático de natureza alcalina saturada, afinidade shoshonítica e idade mais antiga (Stabel et al 2001). Neste trabalho, ambos sienitos são considerados sob a denominação de Suíte Piquiri.

SIENITOS PIQUIRI E ARROIO DO SILVA O Sienito Piquiri tem cerca de $130 \mathrm{~km}^{2}$ e é intrusivo em uma sequîência vulcanosedimentar do estágio pós-colisional do Ciclo Brasiliano. O sienito tem idade estimada em ca. de $600 \mathrm{Ma}$, com base nas datações K/Ar $(580 \pm 25 \mathrm{Ma}), \mathrm{Rb} / \mathrm{Sr}(606 \pm 98 \mathrm{Ma}$, Ro $=0,706 \pm$ $0,000013, \mathrm{MSWD}=0,33$; apud. Soliani Jr. 1986) e nas relações de campo. O sienito foi intrudido pelo Complexo Granítico Encruzilhada (Bitencourt et al. 1993), de idade U-Pb de 594 \pm 5 Ma (Babinski et al. 1997) e ocorre como clastos em conglomerados de topo da Formação Arroio dos Nobres. A granulação do sienito varia de grossa no centro a fina nas bordas (Jost et al. 1985, Stabel et al. 2001), e sua composição varia, no mesmo sentido, de álcali-feldspato-quartzo-sienito e álcali-feldspato-sienito a quartzo-sienito, álcali-feldspato-sienito, sienito, álcalifeldspato-quartzo-sienito, quartzo-monzonito e monzogranito. $\mathrm{O}$ corpo tem proeminente foliação de fluxo ígneo dada pela orientação dos cristais de feldspato, minerais máficos e de enclaves máficos microgranulares (Jost et al. 1985). Vieira Jr. et al. (1989) sugerem que o corpo tem afinidade shoshonítica, corroborada por dados geoquímicos e mineralógicos (Stabel et al. 2001). Para estes autores, os dados geoquímicos são indicativos de que este magmatismo não é contemporâneo com a Suíte Encruzilhada do Sul. Plá Cid et al. (2001), com base em dados de química mineral de enclaves lamprofíricos do sienito concluem que os magmas sieníticos e lamprofíricos são contemporâneos e provêm do manto, de profundidades equivalentes a pressões mínimas de 3 Gpa. A amostra do Sienito Piquiri datada provêm de pedreira de extração de rocha omamental localizada ao norte do município de Encruzilhada do Sul (coordenadas UTM: N6641580 e E-0332071).

A Suíte Intrusiva Arroio do Silva, descrita por UFRGS (1992), consiste de pequenos corpos plutônicos sieníticos, localmente dioritos, localizados a NE da cidade de Encruzilhada do Sul. Embora as relações estratigráficas e os dados petro-gráficos sugiram sua correlação com o Sienito Piquiri, os dados disponíveis ainda são precários. A amostra selecionada foi extraída de aflo-ramento situado a sul da cidade de Encruzilhada do Sul (coordenadas UTM: N-6622050 e E-0359081).

Suíte Dom Feliciano Esta é a suíte mais jovem do batólito e, embora seus granitos apresentem composição muito próxima das observadas nas suítes Viamão e Encruzilhada do Sul, seu posicionamento é posterior às estruturas transcorrentes do evento $\mathrm{D}_{2}$. A suíte ocupa cerca de $20 \%$ da área do batólito e suas exposições se concentram na porção norte do mesmo. Possui contato tectônico à W com a Suíte Cordilheira, e é intrusiva nas suítes Pinheiro Machado e Viamão e no Complexo Gnáissico Arroio dos
Ratos. O principal corpo da suíte é alongado segundo N50"$60^{\circ} \mathrm{E}$, tem cerca de $180 \mathrm{~km}$ de comprimento e entre $15 \mathrm{~km}$ e $45 \mathrm{~km}$ de largura. Os corpos da mesma, embora concordantes com as zonas de cisalhamento $\mathrm{D}_{2}$, colocaram-se posteriormente a atividade principal destas estruturas, como sugere a sua incipiente deformação dúctil. A suíte tem grande homogeneidade composicional, estrutural e petrográfica, e raramente contém enclaves microgranulares máficos e micáceos. Os leucogranitos da suíte são rosados, castanhos e cinza claros. Predominam sienogranitos, aos quais se subordinam ortoclásio-microclínio granitos, quartzo-sienitos e sienitos. Os minerais essenciais são o ortoclásio e/ou microclínio subédrico e quartzo amebóide, com biotita sub-édrica (1 a $4 \%$ ) intersticial. Os minerais acessórios são allanita, zircão, titanita, apatita e minerais opacos, por vezes também fluorita, molibdenita e galena. Na região de Dom Feliciano, o granito homônimo apresenta contatos lobados com o Diorito Capim Branco, sugerindo relação de contemporaneidade com o mesmo (Wildner et al. 1994). A semelhança composicional e geoquímica entre os granitos mais diferenciados da suíte e os diques de riolito e rochas piroclásticas que ocorrem sobre o batólito, sugere o vínculo genético entre ambos (Philipp 1998). Os enxames de diques félsicos das regiões de Porto Alegre, Mariana Pimentel, Canguçu, Piratini, Pinheiro Machado estão intimamente associados com diques máficos, constituindo diques compostos (Philipp et al. 1995, Philipp 1998). A relação dos diques com os granitos da suíte é, até o momento, apenas espacial e carece de dados que permitam a sua correlação.

GRANITO CAPÃO DO LEÃO O Granito Capão do Leão aflora a $\mathrm{W}$ da cidade de Pelotas como corpo subarredondado, com cerca de $10 \mathrm{~km}$ de diâmetro. Trata-se de leucogranito rosa-avermelhado, com textura equigranular hipidiomórfica grossa a média. Apresenta estrutura maciça e é composicional e es-truturalmente homogêneo. Apresenta, por vezes, foliação magmática dada pelo alinhamento de cristais de feldspato potássico. Contém raros enclaves microgranulares máficos, arredondados e com dimensões entre 2 a $15 \mathrm{~cm}$.

A sua composição dominante é sienogranítica, sendo constituído essencialmente por feldspato potássico róseo e subedral e quartzo amebóide. O plagioclásio é branco e prismático equidimensional. A biotita é rara e intersticial. Titanita, zircão, apatita, allanita, granada e minerais opacos são acessórios. A amostra selecionada para a datação foi retirada de pedreira situada a nordeste da cidade de Capão do Leão (coordenadas UTM: N-6482502 e E-0357820).

GRANITO BELA VISTA O Granito Bela Vista (Philipp et al. 1991) é uma intrusão elíptica, com eixo maior de $5,5 \mathrm{~km}$ e menor de $1,5 \mathrm{~km}$, orientada segundo $N 50^{\circ} \mathrm{E}$. Sua colocação também foi controlada por zona de cisalhamento rúptil (N40$50^{\circ} \mathrm{E}$ ), mas mais rasa do que os anteriores, em nível epizonal. A movimentação desta estrutura desenvolveu protocataclasitos na intrusão. O contato do Granito Bela Vista com a SV é claramente de intrusão, como indicam os diques de microgranítico e riolito que cortam as encaixantes segundo N10$20^{\circ} \mathrm{W}$.

Dados petrográficos permitiram individualizar três fácies, isto é, a equigranular; a porfirítica e a microgranítica porfi- 
rítica. As rochas são, em geral, rosadas, com pontuações escuras de anfibólio. A fácies predominante é a equigranular, cuja textura é hipidiomólfica grossa e composta de feldspato potássico subédrico, subordinadamente quartzo e minerais máficos anédricos. No extremo NE, o granito adquire textura porfirítica a heterogranular marcada por fenocristais tabulares de feldspato potássico (2 a $4 \mathrm{~cm}$ ), em até $50 \%$ da rocha, imersos em matriz equigranular hipidiomórfica grossa, com quartzo e anfibólio. Na margem SW do corpo, a rocha é um microgranito castanhoescuro, que caracteriza a sua margem resfriada, com textura porfirítica dada por poucos fenocristais de feldspato potássico (5 a $10 \mathrm{~mm}$ ), em matriz equigranular fina a muito fina composta por feldspato potássico, quartzo, clinopiroxênio e anfibólio. A estrutura do corpo é maciça, sendo interrompida apenas na porção $S W$ por abundantes fraturas $N 10-40^{\circ} \mathrm{W}$ e N $15-50^{\circ} \mathrm{E}$ preenchidas com diques de microgranito, riolito e máficos de $2 \mathrm{~m}$ a $10 \mathrm{~m}$ de largura.

Petrograficamente predominam pertita-granitos, pertita-quartzo sienitos e pertita sienitos. Os minerais essenciais compreendem feldspato alcalino mesopertítico e quartzo, subordinadamente clinopiroxênio, anfibólio sódico-cálcico e biotita. Os minerais acessórios compreendem zircão, apatita, allanita, magnetita e ilmenita. O principal mineral máfico é um anfibólio do tipo Fe-Winchita. A riebeckita é tardia, acicular e dimensões reduzidas. Na margem resfriada do corpo e em alguns diques de microgranito, ocorre clinopiroxênio verde (hedenbergita). A ocorrência de biotita se restringe à margem resfriada, onde parcialmente substitui o clinopiroxênio e o anfibólio, e é subédrica, com pleocroísmo castanho avermelhado e composição da anita. (Philipp et al. 2002c). A amostra estudada foi retirada de afloramento situado na porção sul do Granito Bela Vista (coordenadas UTM: N-6521801 e E-0293310).

GEOCRONOLOGIA Pb-Pb EM MONOCRISTAIS DE ZIRCÃO Métodos Analíticos O método de datação por evaporação do $\mathrm{Pb}$ de monocristais de zircão foi desenvolvido por Kober $(1986,1987)$, mediante evaporação do chumbo no mineral por sucessivas etapas de aquecimento em espectrômetro de massa por termoionização (TIMS). A composição isotópica do $\mathrm{Pb}$ evaporado em cada etapa de aquecimento é determinada, e a razão ${ }^{207} \mathrm{~Pb} /{ }^{206} \mathrm{~Pb}$ medida permite calcular a idade a partir das equações de desintegração do ${ }^{235} \mathrm{U} \mathrm{e}^{238} \mathrm{U}$ em ${ }^{207} \mathrm{~Pb}$ e ${ }^{206} \mathrm{~Pb}$, respectivamente, como função do tempo. Como os teores de $U$ e $\mathrm{Pb}$ não são determinados, os dados isotópicos não podem ser colocados em diagrama concórdia e, conseqüentemente, o grau de discordância dos pontos analíticos não pode ser avaliado. A idade ${ }^{207} \mathrm{~Pb} /{ }^{206} \mathrm{~Pb}$ deve, portanto, ser considerada como a mínima da cristalização ou recristalização do zircão analisado. Entretanto, vários estudos geocronológicos mostram que, quando as idades calculadas pelas razões isotópicas do $\mathrm{Pb}$ são similares, em várias etapas de aquecimento para um mesmo grão, e em vários cristais distintos, a idade média calculada pode ser interpretada como a idade concordante no diagrama $\mathrm{U}-\mathrm{Pb}$ (Ansdell \& Kyser 1991, Karabinos 1997, Kröner et al. 1998). Os efeitos da metamictização de grãos com alto teor de U, do metamorfismo de alta temperatura e/ou pressão, assim como a presença de chumbo herdado, são os principais complicadores da inter-pretação das idades ${ }^{207} \mathrm{~Pb} /{ }^{206} \mathrm{~Pb}$ (Paquette et al. 1994, Kröner et al. 1994).

Preparação das Amostras e Condições Analíticas Os grãos de zircão das amostras datadas foram encaminhados para o Laboratório de Geologia Isotópica (Pará-ISO), da Universidade Federal do Pará. Os cristais foram selecionados em função da morfologia e estruturas internas. Cada cristal foi introduzido em fillamento de Rênio com forma de canoa, após descrição sucinta de suas características e fotografia digital no microscópio ótico.

As composições isotópicas do chumbo foram determinadas em Espectrômetro de Massa Finnigan MAT 262. O procedimento analítico inclui uma etapa inicial de aquecimento dos filamentos a $1100^{\circ} \mathrm{C} \mathrm{e} 1600^{\circ} \mathrm{C}$ durante 1 minuto, para eliminar o chumbo de contaminação. Em geral, a evaporação do chumbo é efetuada entre $1450^{\circ} \mathrm{C}$ e $1550^{\circ} \mathrm{C}$, com incrementos sucessivos de $20^{\circ} \mathrm{C}$ a $30^{\circ} \mathrm{C}$. O tempo de evaporação foi de cerca de 3 a 5 minutos por etapa. Após cada etapa de evaporação, o chumbo foi ionizado a $1050-1100^{\circ} \mathrm{C}$. As razões isotópicas foram medidas tanto pelo processo dinâmico, utilizando multiplicador de elétron (SEM) e contador de íons, quanto estático, com coletores Faraday para as massas 206,207, 208 e, contador de íons para a massa 204, em função da intensidade do sinal.

Nas análises pelo processo dinâmico com o contador de íons, a sequiência de leitura das massas de $\mathrm{Pb} 206,207,208,206$, 207 e 204 foram medidas em 5 blocos de 10 ciclos, resultando em 100 razões isotópicas ${ }^{207} \mathrm{~Pb} /{ }^{206} \mathrm{~Pb}$. Pelo processo estático (multicoleção), foram utilizados 10 blocos de 10 ciclos cada, que também resultaram em 100 medidas de razões isotópicas ${ }^{207} \mathrm{~Pb} /{ }^{206} \mathrm{~Pb}$. A precisão média das razões isotópicas ${ }^{207} \mathrm{~Pb} /{ }^{206} \mathrm{~Pb}$ é de $0,52 \%(0,16 \%-2,08 \%)$. As razões isotópicas medidas foram corrigidas para o efeito de discriminação de massa por um fator de $0,12 \%$ por unidade de massa atômica. Estas razões foram determinadas a partir de análises repetidas de uma amostra padrão de $\mathrm{Pb}$ (NBS 982). Os blocos com razões ${ }^{206} \mathrm{~Pb} /$ ${ }^{204} \mathrm{~Pb}<2500$ foram descartados do cálculo da média para minimizar o erro introduzido pela correção do chumbo comum. As razões ${ }^{207} \mathrm{~Pb} / 206 \mathrm{~Pb}$ dos blocos não excluídos foram corrigidas para o $\mathrm{Pb}$ comum a partir dos valores fornecidos por Stacey \& Kramers (1975), recalculados na idade do zircão (correção de chumbo inicial). Efetuadas as correções de fracionamento e de $\mathrm{Pb}$ comum, calculou-se a idade para cada etapa de aquecimento e a idade de cada grão a partir da média das etapas que forneceram as idades mais antigas e idênticas, dentro dos limites do erro analítico. A idade final da amostra foi calculada a partir da média ponderada das idades dos grãos. Um elevado número de grãos com idade semelhante assegura a confiabilidade da obtida. O tratamento estatístico dos resultados analíticos e o cálculo da idade e do erro correspondente são descritos por Gaudette et al. (1998).

Os resultados obtidos com as amostras analisadas constam da Tabela 1, a qual exclui os dados de cristais que não forneceram sinal de $\mathrm{Pb}$ suficientemente intenso para a determinação da razão isotópica, assim como os cristais e etapas que forneceram razões ${ }^{206} \mathrm{~Pb} / 204 \mathrm{~Pb}<2500$. O erro nas determinações é expresso pelos desvios padrões $(2 \sigma)$, e também se comenta os valores de USD (Unified Standard Deviation), o qual corresponde à raiz quadrada da MSDW (Mean Square Weighted Deviation), indicativo do grau de dispersão dos pontos e deve ser próximo de 1 . Se superior, é necessário multiplicá-lo pelo valor de USD, se necessário utilizar este desvio (Gaudette et al. 1998).

Resultados Analíticos e Interpretação das Idades Pb-Pb 
Ruy Paulo Philipp et al.

Tabela 1 - Dados isotópicos de Pb obtidos por evaporação de cristais de zircão dos granitos e sienitos do Batólito Pelotas.

\begin{tabular}{|c|c|c|c|c|c|c|c|c|c|c|c|}
\hline Zircão & $\begin{array}{l}\text { Temp. } \\
\text { celsius }\end{array}$ & $\begin{array}{l}\text { Número } \\
\text { Razões }\end{array}$ & $\begin{array}{l}206 \mathrm{~Pb} / \\
204 \mathrm{~Pb}\end{array}$ & $\begin{array}{l}208 \mathrm{~Pb} / \\
206 \mathrm{~Pb}\end{array}$ & $2 s$ & $\begin{array}{l}207 \mathrm{~Pb}^{*} / \\
206 \mathrm{~Pb}^{*}\end{array}$ & $2 s$ & $\begin{array}{c}\text { Idade(Ma) } \\
\text { inicial }\end{array}$ & $2 s$ & $\begin{array}{l}\text { Idade } \mathrm{Mal} \text { ) } \\
\text { Final }\end{array}$ & $2 s$ \\
\hline \multicolumn{12}{|l|}{$\underset{\text { Granod. }}{\underline{S P M}}$} \\
\hline \multirow[t]{2}{*}{$\mathrm{PM} / 01$} & 1450 & 90 & 7519 & 0,10243 & 113 & 0,06051 & 16 & 622 & 6 & & \\
\hline & 1500 & 86 & 25641 & 0,1903 & 765 & 0,06050 & 14 & 622 & 5 & & \\
\hline \multirow{4}{*}{$\mathrm{PM} / 03$} & 1550 & 88 & 25000 & 0,15505 & 42 & 0,06052 & 26 & 622 & 9 & 622 & 4 \\
\hline & 1450 & 66 & 6410 & 0,0583 & 117 & 0,06028 & 21 & 614 & 7 & & \\
\hline & 1500 & 82 & 20408 & 0,1352 & 32 & 0,06034 & 30 & 616 & 11 & & \\
\hline & 1550 & 82 & 18868 & 0.14862 & 215 & 0,06063 & 10 & 626 & 4 & & \\
\hline \multirow{3}{*}{$\mathrm{PM} / 04$} & 1570 & 88 & 12195 & 0,1165 & 55 & 0,06025 & 31 & 613 & 11 & 623 & 6 \\
\hline & 1450 & 90 & 4444 & 0,12125 & 88 & 0,06063 & 22 & 626 & 8 & & \\
\hline & 1500 & 70 & 23810 & 0,19561 & 292 & 0,06093 & 17 & 637 & 6 & & \\
\hline \multirow{5}{*}{ PM/08 } & 1500 & 20 & 24390 & 0,18641 & 250 & 0,06065 & 37 & 627 & 13 & & \\
\hline & 1550 & 52 & 16129 & 0,21874 & 97 & 0,06089 & 27 & 636 & 10 & 633 & 6 \\
\hline & 1450 & 18 & 3922 & 0,04077 & 33 & 0,05779 & 258 & 522 & 98 & & \\
\hline & 1500 & 86 & 6803 & 0,15905 & 163 & 0,06078 & 22 & 632 & 8 & 632 & 8 \\
\hline & & & & & & $\begin{array}{c}\text { Média (900 razões } \\
\text { USD }=2.0)\end{array}$ & & & & 625 & 4 \\
\hline \multicolumn{12}{|l|}{ Gr.Chasa. } \\
\hline Gr.Chasa. & & & & & & & & & & & \\
\hline \multirow[t]{3}{*}{ CHAS $/ 01$} & 1450 & 18 & .59 .52 & 0,10778 & 1.34 & 0,05877 & 131 & .559 & 49 & & \\
\hline & 1500 & 47 & 32258 & 0,15438 & 69 & 0,05918 & 31 & 574 & 11 & & \\
\hline & 1550 & 90 & {$[724]$} & 0,15336 & 52 & 0,05904 & 25 & 569 & 9 & 571 & 7 \\
\hline CHAS/02 & 1500 & 90 & 5556 & 0,22118 & 122 & 0,05905 & 26 & 569 & 9 & 569 & 9 \\
\hline \multirow[t]{2}{*}{ CHAS $/ 03$} & 1450 & 86 & 3279 & 0,13824 & 39 & 0,05866 & 20 & 555 & 8 & & \\
\hline & 1500 & 88 & 11364 & 0,14847 & 36 & 0,05854 & 16 & 550 & 6 & 552 & 5 \\
\hline \multirow[t]{2}{*}{ CHAS/04 } & 1450 & 18 & 3906 & 0,08445 & 45 & 0,05881 & 33 & 560 & 12 & & \\
\hline & 1500 & 90 & 18519 & 0,10899 & 104 & 0,05907 & 10 & 570 & 4 & & \\
\hline \multirow{3}{*}{ CHAS/05 } & 15.50 & 86 & 8.3 .33 & $0,1.5336$ & 98 & 0,05819 & 20 & 537 & 7 & 569 & 5 \\
\hline & 1500 & 84 & 11111 & 0.15124 & 61 & 0,05919 & 21 & 574 & 8 & & \\
\hline & 1550 & 84 & 14925 & 0,14983 & 54 & 0,05932 & 24 & 579 & 9 & 576 & 6 \\
\hline CHAS/06 & 1450 & 32 & 4444 & 0,13786 & 53 & 0,05969 & 42 & 593 & 15 & 593 & 15 \\
\hline \multirow[t]{2}{*}{ CHAS/11 } & 1450 & 84 & 3247 & 0,17773 & 61 & 0,05873 & 21 & 558 & 8 & & \\
\hline & 1500 & 84 & 8850 & 0,16758 & 41 & 0,05899 & 34 & 567 & 12 & 560 & 9 \\
\hline $\mathrm{CH} A \mathrm{~S} / 12$ & 1500 & 88 & 4808 & 0,18693 & 84 & 0,05920 & 40 & 575 & 15 & 575 & 15 \\
\hline $\mathrm{CH} \Lambda \mathrm{S} / 13$ & 1430 & 18 & 7246 & 0,15386 & 117 & 0,05943 & 47 & 583 & 17 & & \\
\hline & 1450 & 90 & 18182 & 0,16521 & 48 & 0,05907 & 19 & 570 & 7 & & \\
\hline & 1490 & 88 & 18182 & 0,16711 & 40 & 0,05925 & 15 & 576 & 5 & 574 & 5 \\
\hline CHAS/14 & 1480 & 52 & 166667 & 0,16131 & 218 & 0,05993 & 23 & 601 & 8 & & \\
\hline & 1500 & 84 & 50000 & 0,16978 & 74 & 0,06018 & 14 & 610 & 5 & 608 & 8 \\
\hline CHAS $/ 15$ & 1480 & 48 & 10204 & 0,18568 & 217 & 0,05911 & 27 & 571 & 10 & 571 & 10 \\
\hline CHAS/16 & 1450 & 16 & 29412 & 0,18622 & 102 & 0,06070 & 40 & 629 & 14 & 629 & 14 \\
\hline & & & & & & $\begin{array}{c}\text { Média }(1361 \text { razões, } \\
\text { USD }=4.9\end{array}$ & & & & 575 & 8 \\
\hline Zircão & Temp. & Número & $206 \mathrm{~Pb} /$ & $208 \mathrm{~Pb} /$ & $2 s$ & $207 \mathrm{~Pb} \% /$ & $2 s$ & Idade(Ma) & $2 s$ & Idade $\mathrm{M}(\mathrm{l})$ & $2 s$ \\
\hline & celsius & Razões & $204 \mathrm{~Pb}$ & $206 \mathrm{~Pb}$ & & $206 \mathrm{~Pb}^{*}$ & & inicial & & Final & \\
\hline$\frac{S I P}{S i l v a}$ & & & & & & & & & & & \\
\hline$\frac{\text { S.A. Silvat }}{\text { ASI } / 01}$ & & & & & & & & & & & \\
\hline & $\begin{array}{l}14.50 \\
1500\end{array}$ & $\begin{array}{l}70 \\
36\end{array}$ & $\begin{array}{c}8696 \\
18868\end{array}$ & $\begin{array}{l}0,13519 \\
0,18518\end{array}$ & $\begin{array}{l}124 \\
181\end{array}$ & $\begin{array}{l}0,05979 \\
0,06026\end{array}$ & 25 & $\begin{array}{l}590 \\
613\end{array}$ & $\begin{array}{l}0 \\
9\end{array}$ & & \\
\hline & 1550 & 88 & 22727 & 0,19830 & 52 & 0,06032 & 18 & 615 & 7 & & \\
\hline & 1570 & 90 & 166667 & 0,19543 & 82 & 0,06010 & 24 & 607 & 9 & 612 & 5 \\
\hline ASI $/ 02$ & 1450 & 18 & 7519 & 0,11238 & 72 & 0,06040 & 67 & 618 & 24 & & \\
\hline & 1500 & 82 & 8264 & 0,17746 & 126 & 0,06047 & 26 & 621 & 9 & & \\
\hline & 1550 & 36 & 11364 & 0,20910 & 140 & 0,06071 & 33 & 629 & 12 & 624 & 7 \\
\hline ASI $/ 03$ & 14.50 & 32 & 8475 & $0,1279 I$ & 82 & 0.05960 & 52 & 589 & 19 & & \\
\hline & 1500 & 90 & 27778 & 0,16609 & 67 & 0,06013 & 12 & 609 & 4 & 609 & 4 \\
\hline ASI/04 & 1500 & 84 & 6452 & 0,17131 & 87 & 0,06022 & 17 & 612 & 6 & & \\
\hline & 1550 & 86 & 12195 & 0,19605 & 57 & 0,05999 & 17 & 603 & 6 & 608 & 9 \\
\hline ASI/05 & 1450 & 90 & 3460 & 0,12199 & 68 & $0,062.32$ & 27 & 685 & 9 & & \\
\hline & 1500 & 86 & 15625 & 0,20151 & 90 & 0,06020 & 16 & 611 & 6 & & \\
\hline & 1550 & 82 & 200000 & 0,22344 & 88 & 0,06035 & 13 & 616 & 5 & 614 & 5 \\
\hline ASI/06 & 1450 & 82 & 4237 & 0,16595 & 133 & 0,06018 & 20 & 610 & 7 & & \\
\hline & 1500 & 48 & 22727 & 0,18689 & 43 & 0,06048 & 41 & 621 & 15 & & \\
\hline & 1550 & 88 & 52632 & 0,19391 & 67 & 0,06030 & 26 & 615 & 9 & 613 & 5 \\
\hline ASI/08 & 1450 & 18 & 17544 & 0,14596 & 219 & 0,06007 & 35 & 606 & 13 & & \\
\hline & 1500 & 66 & 24390 & 0,18679 & 162 & 0,06021 & 39 & 611 & 14 & & \\
\hline & 1550 & 54 & 18868 & 0,23021 & 71 & 0,05983 & 68 & 598 & 25 & 607 & 9 \\
\hline & & & & & & $\begin{array}{c}\text { Média (948 razões } \\
\text { USD }=1.4 \text { ) }\end{array}$ & & & & 612 & 3 \\
\hline
\end{tabular}


Tabela 1 - continuação...

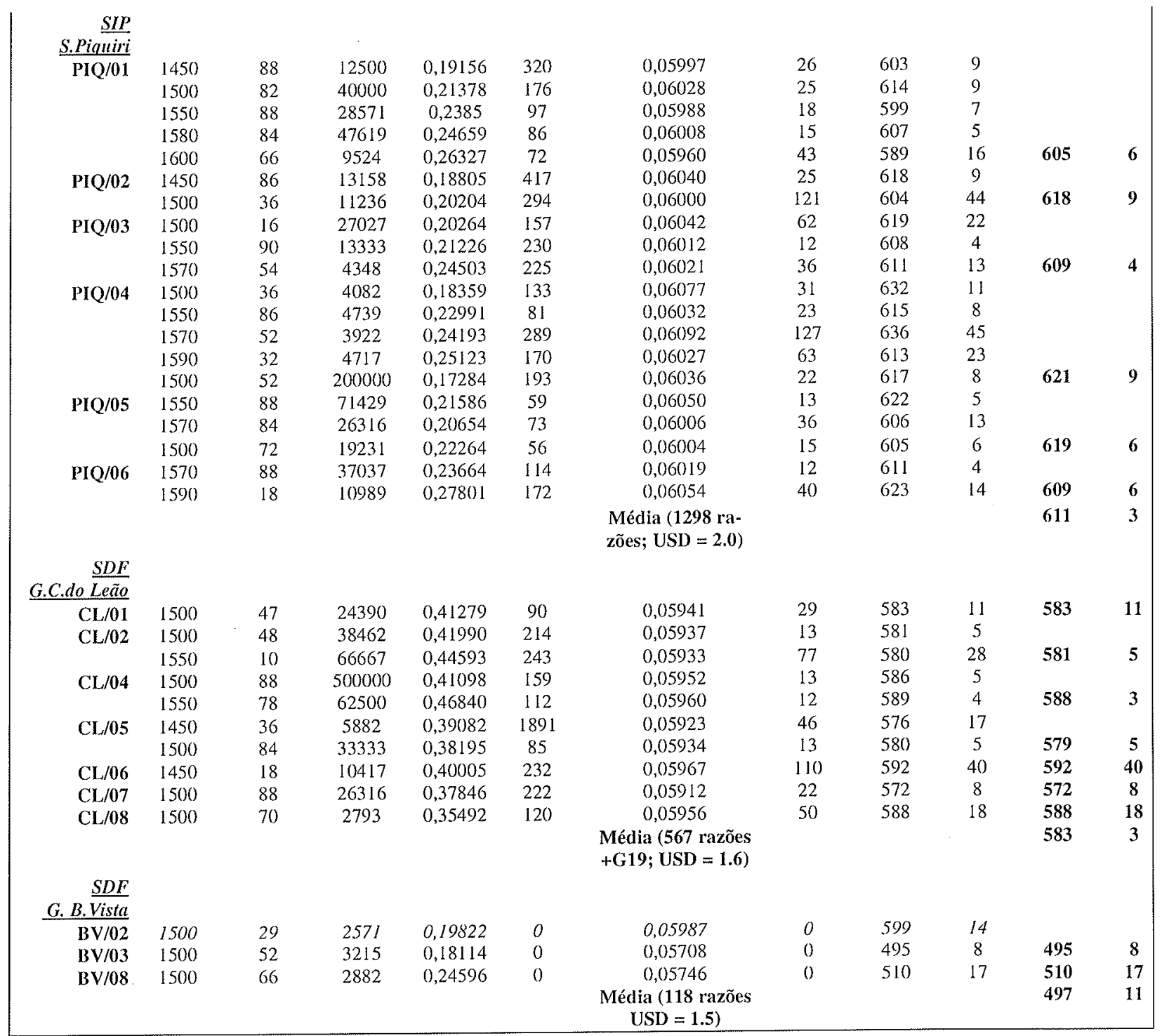

* Pb radiogênico corrigido a partir do $\mathrm{Pb}$ comum; itálico= excluido do cálculo da idade

SUÍTE PINHEIRO MACHADO Os cristais de zircão do granodiorito da suíte são prismas bem desenvolvidos, alongados e idiomórficos, geralmente apresentam inclusões e alguns são zonados. Dos sete cristais selecionados para análise, apenas 4 foram aproveitados. Todos cristais forneceram mais de uma etapa de evaporação. Exceto o cristal PM/08, todas as etapas de aquecimento foram aproveitadas para o cálculo da idade. Dois cristais forneceram idades em torno de $622 \mathrm{Ma}$ e dois ao redor de 633 Ma. Optou-se por incluir os 4 cristais no cálculo da média de idade, o que resultou em $625 \pm 4 \mathrm{Ma}$ (USD $=2,0$; 900 razões), interpretada como a de cristalização do granodiorito da SPM. Entretanto, idade em torno de 633 Ma não deve ser descartada. Estes resultados são compatíveis com as idades U-Pb obtidas ante-riormente por Babinski et al. (1997).

SIENITO PIQUIRI (Suite Piquiri) Os cristais de zircão do Sienito Piquiri são límpidos, idiomórficos e apresentam muitas fraturas e inclusões. De oito cristais, apenas seis forneceram sinal de $\mathrm{Pb}$ suficiente para a determinação das razões isotópicas. Todos os cristais forneceram várias etapas de aquecimento (de 2 até 5 etapas), sem variações significativas de idade entre as etapas para um mesmo cristal. A idade média calculada a partir de todos os cristais é de $611 \pm 3 \mathrm{Ma}$ (USD $=2,0 ; 1298$ razões). Entretanto, 3 grãos forneceram idades entre 605-609 Ma e 3 entre 618-621 Ma, diferença esta que pode ser relacionada a uma pequena perda de $\mathrm{Pb}$ nos cristais de menor idade ou, ao contrário, pela presença de pequena quantidade de $\mathrm{Pb}$ herdado nos cristais com idade maior. Como as idades dos cristais são estatisticamente semelhantes e situadas no intèrvalo de erro, é razoável assumir que a cristaliação do sienito ocorre um em $611 \pm 3 \mathrm{Ma}$, mas análises adicionais de zircão dessa amostra seriam necessárias para justificar, ou não, a presença de dois grupos de idades distintas.

SIENITO ARROIO DO SILVA (Suíte Piquiri) Os cristais de zircão do sienito são prismáticos, alongados, límpidos e sem 
feições metamícticas. Selecionou-se 7 cristais para análise, os quais forneceram mais de uma etapa de evaporação, com resultados reprodutíveis de uma etapa para outra e de um grão para outro. Os dados fornecem idade de $612 \pm 3 \mathrm{Ma} \mathrm{(2 \sigma )}$ (USD $=1.4$, a partir de 948 razões), interpretada como a de cristalização do sienito. O cristal ASI/05 forneceu, na primeira etapa de evaporção, idade de $685 \pm 9 \mathrm{Ma}$, significativamente mais velha que a dos demais e que pode ser atribuído à presença de $\mathrm{Pb}$ herdado ou à correção imprecisa do $\mathrm{Pb}$ comum.

\section{GRANITO CHASQUEIRO (Suite Viamão) Deste granito} foram selecionados 12 cristais de zircão para a análise. Os cristais são alongados, subeudrais, com prisma bem desenvolvido. Alguns apresentam zoneamento e muitas inclusões. Todos cristais forneceram sinal de $\mathrm{Pb}$ em várias etapas de aquecimento. Exceto o cristal da amostra Chas/01, os demais forneceram idade semelhante em todas as etapas de aquecimento, com variação importante entre os cristais, desde $522 \mathrm{Ma}$ (Chas/03) até $629 \mathrm{Ma}$ (Chas/16). A média da idade calculada a partir dos cristais analisados situa-se em $575 \pm 8$ Ma com USD $=4,9$ (1361 razões) que reflete a variação das idades.

GRANITO CAPÃO DO LEÃO (Suíte Dom Feliciano) Da amostra deste granito selecionou-se 8 cristais de zircão, os quais são prismáticos, límpidos e fraturados. Os cristais forneceram, no máximo, uma ou duas etapas de evaporação, com resultados de aquecimento semelhantes, e geração de idade de $583 \pm 3$ $\mathrm{Ma}(2 \sigma)(\mathrm{USD}=1.6,567$ razões $)$, interpretada como a de cris- talização do granito.

GRANITO BELA VISTA (Suíte Dom Feliciano) Os cristais de zircão deste granito são euédricos, prismáticos, com muitas fraturas e inclusões. Selecionou-se 9 cristais para análise, mas apenas 3 aproveitáveis, com razões ${ }^{206} \mathrm{~Pb} /{ }^{204} \mathrm{~Pb}$ superiores a 2500. Mesmo assim, obteve-se apenas uma etapa de evaporação em cada cristal, com razão ${ }^{206} \mathrm{~Pb} /{ }^{204} \mathrm{~Pb}$ baixa $(<3500)$. Dois cristais apresentam idades de $495 \pm 8 \mathrm{Ma}$ e $510 \pm 17 \mathrm{Ma}$, com média de $497 \pm 11 \mathrm{Ma}$ (USD $=1,5 ; 118$ razões). O terceiro apresentou idade mais antiga de $599 \pm 14 \mathrm{Ma}$. A interpretação dos resultados é duvidosa. A idade de $497 \pm 11$ Ma pode representar a de cristalização do granito e a de 599 Ma pode refletir a presença de componente herdado de $\mathrm{Pb}$ ou mesmo de correção inadequada do $\mathrm{Pb}$ comum. Alternativa-mente, a idade de $497 \pm 11$ Ma pode corresponder a rejuvenescimento por perda de $\mathrm{Pb}$, enquanto a de $599 \mathrm{Ma}$ uma aproximação à de cristalização, mas ambos de caráter especulativo.

DISCUSSÃO E REVISÃO DOS DADOS ISOTÓPICOS DO BATÓLITO PELOTAS Os dados geocronológicos disponíveis sobre as suítes graníticas do Batólito Pelotas e septos do embasamento provêem de determinações por métodos variados [K-Ar, Rb-Sr, Pb-Pb (TIMS-zircão), U-Pb (TIMSzircão), U-Pb SHRIMP (zircão), Ar-Ar (micas) e Sm-Nd (TDM)]. Os resultados indicam que a duração do magmatismo do batólito foi de cerca de $80 \mathrm{Ma}$, com significativa superposição de intervalos de idades (Fig. 3).

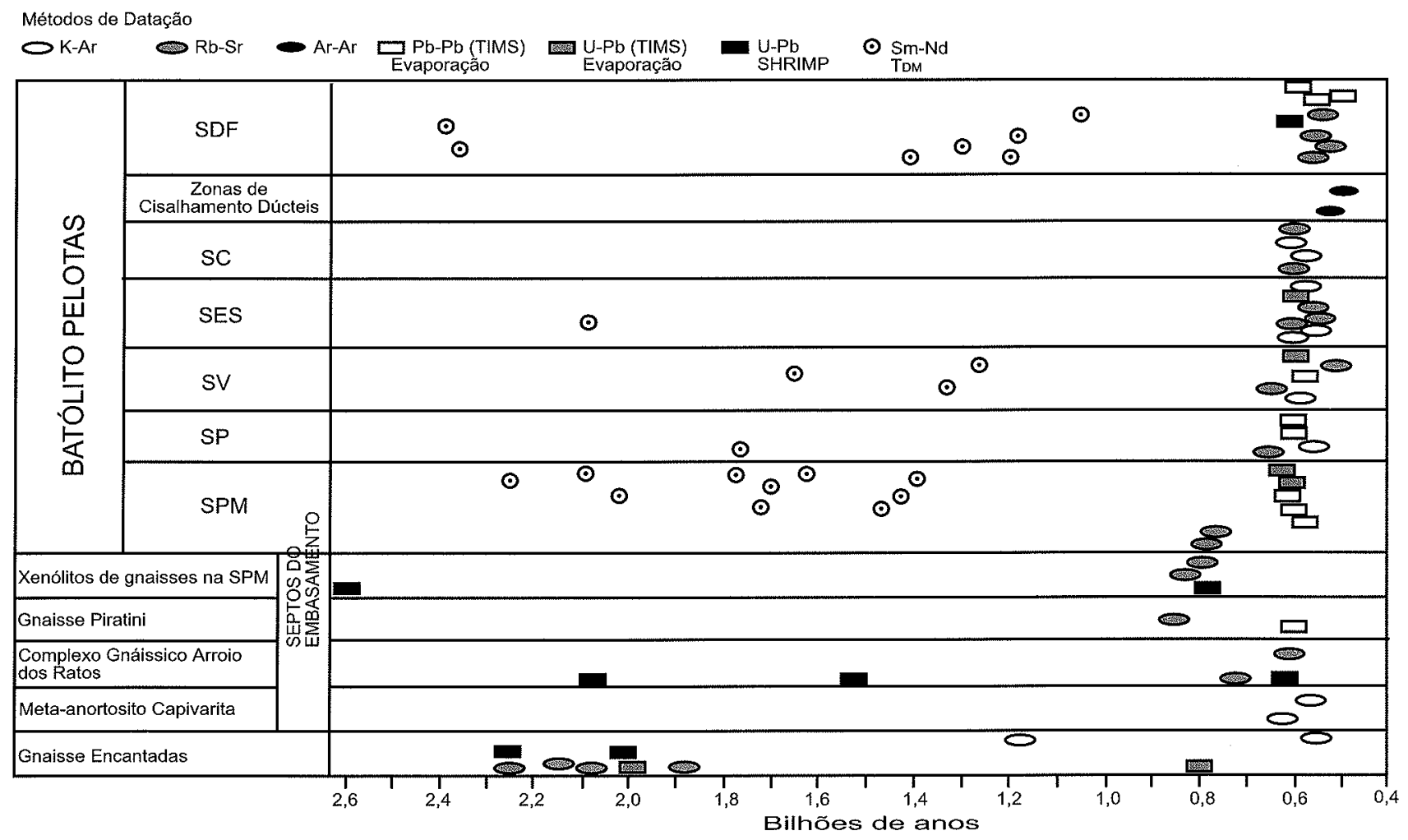

Figura 3 - Sumário das idades isotópicas disponiveis para granitos e sienitos do Batólito Pelotas, dos septos do embasamento e das rochas metamórficas encaixantes. Dados extraídos de Cordani et al. (1974), Teixeira (1982), Soliani.Jr: (1986), May (1990), Fragoso Cesar (1991), Koester (1995), Vasquez(1997), Babinski et al. (1997), Philipp (1998), Silva et al. (1999), Hartmann et al. (2000a), Koester et al. (2001). 
Idades Geocronológicas Os dados $\mathrm{Rb}$-Sr disponíveis sobre a Suíte Pinheiro Machado apontam idades de $750 \mathrm{Ma}$ (Teixeira 1982), $775 \pm 36 \mathrm{Ma}$ (Soliani Jr. 1986) e $572 \pm 54$ Ma (May 1990), e entre 830 a 800 Ma de xenólitos gnáissicos e migmatíticos do batólito (Soliani Jr. 1986). Idades U-Pb em zircão pelo método TIMS forneceram valores de $610 \pm 5$ Ma e $612 \pm$ 2 Ma (Babinski et al. 1997), e de $609 \pm 17$ Ma por SHRIMP em zircão (Hartmann et al. 2000a). Os dados $\mathrm{Pb}-\mathrm{Pb}$ obtidos neste trabalho são compatíveis com os obtidos por Babinski et al. (1997) e Hartmann et al. (2000a), e indicam que a idade de cristalização dos zircões da SIPM situa-se entre 625 a $610 \mathrm{Ma}$. As idades $\mathrm{Rb}-\mathrm{Sr}$ mais antigas obtidas no batólito são, até o momento, desprovidas de significado geológico. Entretanto, podem ser explicadas produto da interação do magma granítico com os septos do embasamento.

Os dados isotópicos da Sluíte Viamão apontam idade U-Pb em zircão (TIMS) de $595 \pm 1 \mathrm{Ma}$, considerada como a de cristalização do Granito Arroio Moinho (Babinski et al. 1997). Koster (1995) obteve uma idade $\mathrm{Rb}-\mathrm{Sr}$ de $672 \pm 22$ Ma para o metagranito Quitéria, e idade U-Pb (TIMS) de $631 \pm 6 \mathrm{Ma}$ (Koster et al. 2001). Este granito foi incluído por Philipp (1998) na SV em função das semelhanças composicionais e estruturais com outros granitos da suíte. Entretanto, a diferença temporal entre os dados disponíveis podem indicar amplo intervalo de geração, ou ainda, que a existência de duas suítes distintas. A idade $\mathrm{Pb}-\mathrm{Pb}$ média de $575 \pm 8 \mathrm{Ma}$ obtida no Granito Chasqueiro, pertencente a esta suíte, deve corresponder ao valor próximo da de sua cristalização, mas elevado valor USD $(4,9)$ impossibilita precisar a idade. Assim, os valores disponíveis sinalizam que o magmatismo principal desta suíte ocorreu entre 580-595 Ma.

Os granitos da Suíte Encurzilhada do Sul geraram idades RbSr de $559 \pm 5 \mathrm{Ma}$ (Soliani Jr. 1986) e $581 \pm 16,8 \mathrm{Ma}$ (Vasquez 1997), e idade U-Pb (TIMS) de $594 \pm 5$ Ma (Babinski et al. 1997). Os dados $\mathrm{Pb}-\mathrm{Pb}$ obtidos neste trabalho apontam idade dos Sienitos Piquiri e Arroio do Silva (SP) mais antiga, como já sugerido pela idade Rb-Sr de $615 \pm 99$ obtida por Soliani Jr. (1986). Deste modo, sugere-se que estes eventos magmáticos são independentes. Cabe ainda ressaltar a diferença composicional entre o magma-tismo sienítico de afinidade shoshonítica, com idade de $612 \pm 3$ Ma e os granitos da SES. Aos sienitos se associam rochas máficas comparáveis com as descritas na Bahia por Conceição et al. (2000) e no Nordeste do Brasil por Da Silva Filho et al. (1993).

Os granitos da Suíte Cordilheira têm idades Rb-Sr de $617 \pm$ $48 \mathrm{Ma}$ e $630 \pm 22 \mathrm{Ma}$, obtidas nos granitos Cordilheira e Arroio Francisquinho, região de Quitéria (Koester 1995), mas a limitada dispersão dos pontos na isócrona e elevado MSWD as tornam apenas como valores de referência. Soma-se a isso, a alteração hidrotermal tardi-magmática destas rochas, resultante da percolação de fluidos ao longo das zonas de cisalhamento que limitam estes corpos.

Os dados Rb-Sr sobre a Suíte Dom Feliciano mostram idades de referência de $572 \pm 10 \mathrm{Ma}$ (Cordani 1974) e $550 \mathrm{Ma}$ (Teixeira 1982), com idade isocrônica de $547 \pm 17 \mathrm{Ma}$ (granitos e pegmatitos da cidade de Cristal), $544 \pm 5 \mathrm{Ma}$ (Granito Arroio dos Ladrões, Soliani Jr. 1986), $550 \pm 6$ Ma dos granitos equigranulares de Cristal e Dom Feliciano (Fragoso Cesar 1991) e $560 \pm 12 \mathrm{Ma}$ dos riolitos da Serra das Asperezas (Soliani Jr. 1986). Recentemente, foi obtida idade U-Pb SHRIMP de 600 $\pm 10 \mathrm{Ma}$ em cristais de zircão do Granito Santana (Koster et al.
2001). A idade $\mathrm{Pb}-\mathrm{Pb}$ de $583 \pm 3 \mathrm{Ma}$, obtida para o Granito Capão do Leão é coerente com dados de campo. Os resultados das idades $\mathrm{Pb}-\mathrm{Pb}$ obtidas no Granito Bela Vista não são conclusivos e dependem de novos dados. Assim, as idades obtidas $(497 \pm 11 \mathrm{Ma}$ e $599 \pm 14 \mathrm{Ma})$ podem ser consideradas apenas como limites mínimo e máximo, e as idades disponíveis sobre esta suíte permitem considerar que o evento magmático responsável pela formação do Batólito Pelotas ocorreu entre $630 \mathrm{Ma}$ e $550 \mathrm{Ma}$.

Razões Isotópicas de ${ }^{87} \mathrm{Sr} /{ }^{86} \mathrm{Sr} \quad$ As amostras representativas da Suíte Pinheiro Machado possuem razões iniciais de ${ }^{87} \mathrm{Sr} /$ ${ }^{86}$ Sr entre 0,7060 e 0,708 (Cordani et al. 1974, Soliani Jr. 1986, Philipp 1998). A Suíte Piquirí tem razão inicial de 0,706 (Sienito Piquiri). Nos granitos da Suíte Encurilhada do Sul, os valores situam-se entre 0,711 a 0,716 (Soliani Jr. 1986, Vasquez 1997), enquanto nas amostras representativas da Suíte Cordilheira, estas razões, mais elevadas, situam-se entre 0,7324 e 0,7406 (Koester 1995). Nos granitóides da Suíte Dom Feliciano, estas variam entre 0,7083 e 0,7140. Assim, as suítes graníticas do Batólito Pelotas apresentam razões iniciais ${ }^{87} \mathrm{Sr} /$ ${ }^{86} \mathrm{Sr}$ elevados que se justificam por forte contribuição crustal (Fig. 4).

Idades Modelo Sm-Nd e $\varepsilon_{\mathrm{Nd}}$ Dados isotópicos de Sm-Nd em amostras da Suíte Pinheiro Machado obtidos por May (1990), Babinski et al. (1997) e Philipp (1998), indicam idades modelo (TDM) entre 1636 e $2010 \mathrm{Ma}$, com valores de $\varepsilon_{\text {Nd }}$ entre $-5,6 \mathrm{e}$ -10. Dados sobre a Suíte Viamão (Granito Arroio Moinho) forneceram idades modelo entre 1275 e $1692 \mathrm{Ma}$, com valores de $\varepsilon_{\text {Nd }}$ negativos, entre -1,31 e -7,6 (May 1990, Babinski et al. 1997). A Suíte Piquirí apresentou valor de $\varepsilon_{\mathrm{Nd}}$ de $-10,9$ e idade modelo $\mathrm{T}_{\mathrm{DM}}$ de $1750 \mathrm{Ma}$ (Babinski et al. 1997). Na Suíte Encruzilhada do Sul (Granito Encruzilhada), as idades modelo situam-se entre 1750 e $2080 \mathrm{Ma}$, com $\varepsilon_{\mathrm{Nd}}$ negativo, entre -11 a -15 (Babinski et al. 1997). Estes mesmos autores obtiveram em amostras da SDF amplo intervalo de idades modelo, entre 985 a $2919 \mathrm{Ma}$, com $\varepsilon_{\mathrm{Nd}}$ entre $-0,3$ e $-9,5$, e intervalo intermediário de -4 e -6 (May 1990, Babinski et al. 1997).

As idades modelo do Batólito Pelotas situam-se preferencialmente no intervalo entre 1600-2200 Ma, subordinadamente entre 1000 e $1400 \mathrm{Ma}$. O primeiro intervalo é correlacionável com as idades dos septos do embasamento e rochas metamórficas situadas à W do batólito (entre 1900 e 2300 Ma) (Fig. 3). Assim como os dados de $\mathrm{Sr}$, os valores de $\varepsilon_{\mathrm{Nd}}$ negativos $(-11$ a - 5) apontam importante contribuição crustal.

CONSIDERAÇÕES FINAIS As datações $\mathrm{Pb}-\mathrm{Pb}$ de monocristais de zircão pelo método da evaporação (TIMS) em quatro suítes do Batólito Pelotas (Pinheiro Machado, Piquirí, Viamão e Dom Feliciano) mostraram idades no intervalo entre 573 e $633 \mathrm{Ma}$, as idades mais antigas ocorrendo nas rochas das suítes Pinheiro Machado (entre 625 e $633 \mathrm{Ma}$ ) e Piquirí (entre 611 e $612 \mathrm{Ma}$ ) e, as mais jovens nas das suítes Viamão (575 Ma) e Dom Feliciano (583 e $500 \mathrm{Ma}$ ). Estes resultados são coerentes com idades disponíveis na literatura e obtidas pelo método U-Pb convencional (TIMS) e U-Pb SHRIMP em zircão (Babinski et al. 1997, Silva et al. 1999, Hartmann et al. 2000a, Koster et al. 2001).

As razões isotópicas iniciais de $\mathrm{Sr}$ são elevadas na maioria das suítes do batólito $(0,708$ a 0,7016$)$ com valores ainda mais 

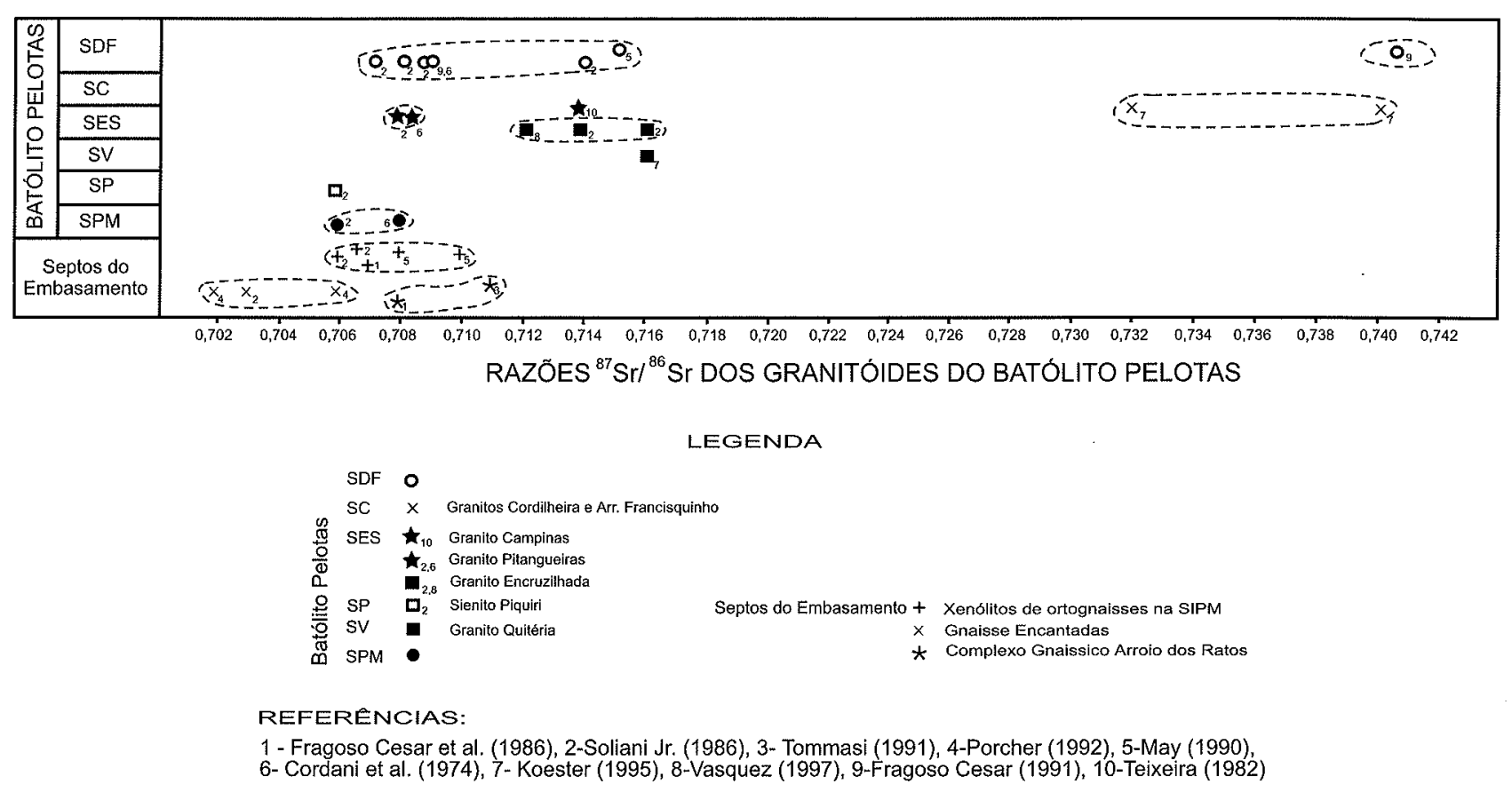

Figura 4-Sumário das razões iniciais de ${ }^{87} \mathrm{Sr}{ }^{\circledR 6} \mathrm{Sr}$ disponíveis para os granitos e sienitos do Batólito Pelotas e para as rochas metamórficas encaixantes.

elevados $(0,732$ a 0,740$)$ nas rochas da Suíte Cordilheira, exceto na Suíte Pinheiro Machado, que apresenta valores mais baixos $(0,706$ a 0,708$)$. Estas razões, associadas a valores de $\varepsilon_{\mathrm{Nd}}$ quase sempre fortemente negativos $(-0,3 \mathrm{a}-15)$, são indicativas de reciclagem de crosta continental, preferencialmente sobre adição de material juvenil. Este modelo parece também se aplicar à Suíte Pinheiro Machado, onde os valores de $\varepsilon_{\mathrm{Nd}}$ também são fortemente negativos (entre $-5,6$ a -10 ). Por outro lado, a presença de magmatismo máfico associado a todas as suítes graníticas do batólito está materializada na preservação de estruturas de misturas homogênea e heterogênea de magmas graníticos, por diversos corpos de rochas máficas mapeáveis e enxames de diques compostos. A significativa presença de magmatismo máfico associado ao granítico sugere importante contribuição mantélica na formaçào do batólito, a exemplo do descrito por Bitencourt \& Nardi (2000) na porção norte do mesmo. Entretanto, ainda não há dados isotópicos do evento máfico.

A relativa coerência entre as idades modelo $\mathrm{T}_{\mathrm{DM}}$ das diferentes suítes graníticas do batólito (1,6 a 2,2 Ga) com as disponíveis das rochas metamórficas situadas na porção oeste do mesmo (entre 1,9 e 2,2 Ga), sugere fusão de crosta Paleoproterozóica como provável fonte dos magmas que originaram o batólito (Philipp 1998, Silva et al. 1999, Philipp et al. 2001b). A avaliação integrada dos dados isotópicos do Batólito Pelotas, em conjunto com as evidências geoquímicas e de campo (Figueiredo et al. 1990, Philipp 1990, 1998, Gomes 1990, Philipp et al. 1993, 1998, 2000, $2001 \mathrm{a}, \mathrm{c})$, indicam que as fontes dos magmas geradores do mesmo foram mistas, envolvendo porções mantélicas metassomatizadas por subducção anterior e sequiên- cias crustais dominadas por ortognaisses. Os dados geocronológicos obtidos por diversos métodos confirmam que as suítes se formaram durante intervalo relativamente restrito, entre 630 $\mathrm{Ma}$ a $550 \mathrm{Ma}$.

Outro aspecto relevante da geração e posicionamento do magmatismo granítico Brasiliano e, provavelmente, de outros cinturões Neoproterozóicos da Plataforma Sul-americana, é o importante papel desempenhado pelas zonas de cisalhamento transcorrentes dúcteis de alto ângulo. Estas foram, aparentemente, instaladas durante o início da história geológica do batólito e exerceram controle tectônico efetivo na geração, ascenção e colocação dos corpos graníticos. Sua presença foi fundamental na evolução e constituição das diferentes suítes que compõem o Batólito Pelotas e o próprio Cinturão Dom Feliciano.

A correlação dos dados estruturais com os dados geocronológicos obtidos neste trabalho e os disponíveis na literatura, permite estabelecer os seguintes intervalos de idades para as zonas de cisalhamento dúcteis regionais: (i) entre 635-610 Ma, para as zonas de cisalhamento oblíquas $\operatorname{Sin}-\mathrm{D}_{1}$, que controlam a colocação da Suíte Pinheiro Machado, (ii) entre 610-590 Ma, as zonas de cisalhamento dúcteis de alto ângulo $\operatorname{Sin}-\mathrm{D}_{2}$, que controlam a colocação das suítes Erval, Viamão e Cordilheira, e (iii) entre 570 e $530 \mathrm{Ma}$, para as zonas de cisalhamento dúctilrúpteis de alto ângulo Tardi- $D_{2}$ e $\operatorname{Sin}-\mathrm{D}_{3}$, que afetam a Suíte Dom Feliciano.

Do exposto conclui-se que a atividade magmática que originou o Batólito Pelotas durou por cerca de $80 \mathrm{Ma}$ (entre 630 $\mathrm{Ma}$ e $550 \mathrm{Ma}$ ), intervalo este que corresponde também ao da atividade das zonas de cisalhamento regionais do Cinturão Dom Feliciano no sul do Brasil e Uruguai. 
As razões isotópicas de $\mathrm{Sr}$ e $\mathrm{Nd}$ apontam para um modelo tectônico com predomínio de fusão de crosta continental paleoproterozóica, com participação reduzida de fonte mantélica. Por outro lado, a presença de magmatismo básico associado ao magmatismo granítico sugere conexão das zonas de cisalhamento com o manto, principal fonte de calor responsável pela fusão crustal. Neste modelo, o desenvolvimento das zonas de cisalhamento dúcteis teria proporcionado o espaço necessário para a ascenção, colocação e coexistência de ambos tipos de magmas, servindo também como meio para a transferência de calor para níveis superiores da crosta.

O regime tectônico mais provável para a geração do magmatismo do Batólito Pelotas é aquele sob condições de crosta continental espessada, momento que sucede a colisão. Nestas condições, o calor oriundo do manto (ou de decaimento radioativo) é transportado por condução aos níveis superiores da crosta, com a fusão parcial extensiva ocorrendo somente após a fase compressiva e o pico principal da pressão (England \& Thompson 1984, 1986). Neste modelo térmico, as primeiras fusões ocorrem inicialmente na base da crosta, com o magma máfico (do manto litosférico) desempenhando papel importante como alimentador da fusão e transferência de calor. Posteriormente, passam a ocorrer fusões em níveis crustais mais superiores. Este modelo é compatível com um regime tectônico pós-colisional. Admite-se portanto, que a formação do Batólito Pelotas corresponde principalmente ao estágio pós-colisional, relacionado à evolução final do Ciclo Brasiliano/Pan-Africano na porção sul da Plataforma Sul-Americana.

Agradecimentos À FAPERGS (Proc. No 99/19759) e à FAPESP (Proc. N ${ }^{\circ} 1999 / 10207-2$ ) pelo suporte financeiro aos trabalhos de campo e laboratório, ao CNPq (Proc. No 300423/ 82-9, de Romulo Machado) pela bolsa de produtividade e aos revisores da $R B G$ pelas sugestões ao original.

\section{Referências}

Ansdell K.M. \& Kyser T.K. 1991. Plutonism, deformation, and metamorphism in the Proterozoic Flin Flon greenstone belt, Canada: Limits on timing provided by the single-zircon Pb-evaporation technique. Geology, 19:518-521.

Babinski M., Chemale Jr. F., Van Schmus W.R., Hartmann L.A., Silva L.C. 1997. U-Pb and Sm-Nd geochronology of the Neoproterozoic Granitic-Gneissic Dom Feliciano Belt, Southern Brazil. J. Sou. Am. Ear: Sci., 10:263-274

Bitencourt M.F. \& Nardi L.V.S. 2000. Tectonic setting and sources of magmatism related to the Southern Brazilian Shear Belt. Rev. Bras. Geoc., 30:184-187.

Bitencourt M.F., Gastal M.C.P., Kirchein R.E., Costa K.B., Toledo F.A.L. 1993. Reavaliação preliminar das relações estratigráficas do Complexo Granítico Encruzilhada (CGE), RS. In: Simp. Intern. Neoproterozóico-Cambrico de la Cuenca del Plata, l, Las PalomasMinas, Bol. Res. Expandidos, v.2, n³4, 6p.

Chemale Jr. F. \& Babinski M. 1995. U-Pb zircon dating of deformational events from the Neoproterozoic rocks in the Eastern Brazil. In: SBG, Simp. Nac. Est. Tectôn., 5, Gramado, Bol. Res. Expandidos, pp.: $377-378$.

Chemale Jr. F., Babinski M., Van Schmus W.R., Wildner W., Lima E.F. 1997. U-Pb and Sm-Nd isotopic studies of Neoproterozoic to Early Paleozoic belts in southern Brazil. In: Sou. Am. Symp. Isotope Geology, 1, Campos do Jordão, Extended Abstracts, IG-USPCPGeo, v.1, p. 71 .

Chemale Jr. F. 2000. Evolução Geológica do Escudo Sul-rio-grandense. In: M. Holz \& L.F. De Ros (eds.) Geologia do Rio Grande do Sull. CIGO-UFRGS, Porto Alegre, pp.:13-52.

Cocherie A. 1998. Datations effectuées dans le cadre du projet "Cartographie géologique du sud-est de la Guinée". Compte rendu technique BRGM. 40p.

Conceição R.V., Nardi L.V.S., Conceição H. 2000. The Santanápolis Syenite: genesis and evolution of Paleoproterozoic shoshonitic syenites in northeastern Brazil. Intern. Geol. Review, 42:1-17.

Cordani U.G., Halpern M., Berenholc M. 1974. Comentários sobre as determinações geocronológicas da folha Porto Alegre. In: Carta Geológica do Brasil ao Milionésimo, folha Porto Alegre (SH-22) e folha Lagoa Mirim (S1-22), Brasília, DNPM, Ministério das Minas e Energia, p.70-84.
Da Silva Filho A F., Guimarães I.P., Thompson R.N. 1993. Shoshonitic and ultrapotassic Proterozoic intrusive suites in the CachoeirinhaSalgueiro belt, northeast Brazil: a transition from collisional to postcollisional magmatism. Prec. Res., 62:323-342.

England P.C. \& Thompson A.B. 1984. Pressure-temperature-time paths of regional metamorphism I: heat transfer during the evolution of regions of thickened continental crust. J. Petrol., 25:894-928.

England P.C. \& Thompson A.B. 1986. Some thermal and tectonic models for crustal melting in continental collision zones. In: M.P. Coward \& A.C. Ries (eds.) Collision Tectonics, Geol. Soc., London, Sp. Publ., 19:83-94.

Fernandes L.A., Tommasi A., Porcher C.C. 1990. Esboço estrutural de parte do Batólito Pelotas, região de Quitéria-Capivarita. Acta Geol. Leopold., 30:117-138.

Figueiredo M.C.H., Fragoso Cesar A.R.S., Kronberg B.L. 1990. Litogeoquímica das principais unidades do Batólito Pelotas no Rio Grande do Sul. In: SBG, Cong. Bras. Geol., 36, Natal, Anais, 4:1623-1738.

Fragoso Cesar A.R.S. 1991. Tectônica de placas no Ciclo Brasiliano: as orogenias dos Cinturoses Dom Feliciano e Ribeira no Rio Grande do Sul. Instituto de Geociências, Universidade de São Paulo, São Paulo, Tese de Doutoramento, 362p.

Fragoso Cesar A.R.S., Figueiredo M.C.H., Soliani Jr. E., Faccini U.F. 1986. O Batólito Pelotas (Proterozóico Superior/Eo-Paleozóico) no Escudo do Rio Grande do Sul. In: SBG, Congr. Bras. Geol., 34, Goiânia, Anciis, 3:1322-1343.

Frantz J.C. \& Remus M.V.D. 1986. Geologia da região de CanguçuTorrinhas, RS: caracterização petrográfica, estrutural e estratigráfica. In: SBG, Cong. Bras. Geol., 34, Goiânia, Anciis, 2:931-947.

Frantz J.C. \& Botelho N.F. 1997. Os granitóides Neoproterozóicos do Cinturão Dom Feliciano no extremo sul do Brasil Implicações geotectônicas para a Faixa Leste. In: SBG, Simp. Nac. Est. Tectônicos, 6, Pirenopólis, Bol. Res. Expandidos. 1:4547.

Formoso M.L.L. 1973. Geologia da Folha de Capivarita, RS. Instituto de Geociências, Universidade de São Paulo, São Paulo, Tese de Doutorado, 226p. 
Gaudette H.E., Lafon J.M., Macambira M.J.B., Moura C.A.V., Scheller T. 1998. Comparison of single filament $\mathrm{Pb}$ evaporation/ ionization zircon ages with conventional $\mathrm{U}-\mathrm{Pb}$ results: Examples from the Precambrian of Brazil. J. Sou. Am. Ear:Sci., 11:351363.

Gomes M.E.B. 1990. Petrologia do Granito Arroio Moinho, Canguçu $(R S)$ : geoquímica e deformação. Instituto de Geociências, Universidade Federal do Rio Grande do Sul, Porto Alegre. Dissertação de Mestrado, 199p.

Hallinan S.E., Mantovani M.S.M., Shukowski W., Braggion Jr. I. 1993. Estrutura do Escudo Sul-brasileiro: uma revisão através de dados gravimétricos e magnetométricos. Rev. Bras. Geoc. 23:201-214

Hartmann L.A., Leite J.A.D., da Silva L.C., Remus M.V.D., McNaughton N.J., Groves D.I., Fletcher I.R., Santos J.O.S., Vasconcellos M.A.Z. 2000. Advances in SHRIMP geochronology and their impact on understanding the tectonic and metallogenic evolution of southern Brazil. Austrr J. Ear. Sci. 47:829-844.

Jost H., Brod J.A., Holz M., Kuhn A., Flor M.A.D., Kronbauer A., Dillenburg S. 1985. Geologia estrutural, petrografia e petrologia do sienito Piquiri (Proterozóico Superior), Rio Grande do Sul. In: SBG, Simp. Sul-Bras. Geol., 2., Florianópolis. Anais, pp.: 63-80.

Karabinos P. 1997. An evaluation of the single-grain evaporation method in highly discordant samples. Geoch. Cosmoch. Acta, 61:2467-2474

Kober B. 1986. Whole grain evaporation for ${ }^{207} \mathrm{~Pb} / 206 \mathrm{~Pb}$ age investigations on single zircons using a double filament source. Contrib. Min. Petrol., 93:482-490.

Kober B. 1987. Single grain evaporation combined with $\mathrm{Pb}+$ emitter bedding for $207 \mathrm{~Pb} / 206 \mathrm{~Pb}$ investigations using thermal ion mass spectrometry, and implications for zirconology. Contr. Min. Petrol., 96:63-71.

Koester E. 1995. Petrologia e geocronologia dos granitóides sintectônicos à Zona de Cisalhamento Dorsal de Canguçu. Porto Alegre, Instituto de Geociências, Universidade Federal do Rio Grande do Sul, Dissertação de Mestrado, 240p.

Koester E., Soliani Jr. E., Leite J.A.D., Hartmann L.A., Fernandes L.A.D., McNaughton N.J., Santos J.O.S., Oliveira L.D. 2001. SHRIMP U-Pb age for the emplacement of the Santana Granite and reactivation of the Porto Alegre Suture, southern Brazil. J. Sou. Am. Ear: Sci., 14:91-99.

Kröner A., Cui W.Y., Wang C.Q., Nemchin A.A. 1998. Single zircon ages from high-grade rocks of the Jianping Complex, Liaoning Province NE China. J. Asian EarSci., 16(5-6):519-532.

Kröner A., Jaeckel P., Williams I.S. 1994. Pb-loss patterns in zircons from a high-grade metamorphic terrain as revealed by different dating methods: $\mathrm{U}-\mathrm{Pb}$ and $\mathrm{Pb}-\mathrm{Pb}$ ages for igneous and metamorphic zircons from northern Sri Lanka. Prec. Res., 66: $151-181$

Lafon J.M. 1999. Datations SHRIMP U-Pb sur zircons effectuées dans le cadre du projet "Cartographie géologique du sud-est de la Guinée”. Compte rendu technique. Pará-Iso/UFPa. 11 p.

Leite J.A.D., Hartmann L.A., Fernandes L.A..D., McNaughton N.J., Soliani Jr. E., Koester E., Santos J.O.S., Vasconcellos M.A.Z. 2002. Zircon U/Pb SHRIMP dating of gneissic basement of Dom Feliciano Belt, southernmost Brazil. J. Sou. Am. Ear: Sci. (submetido).

Ludwig K.R. 1980. Calculation of uncertainties of U-Pb data. Earth Planet. Sci. Lett., 46:212-220.

May G.E. 1990. Pan-African magmatism and regional tectonics of
South Brazil. Open University, Milton Keynes, Ph.D. Thesis, 343p.

Paquette J-L, Nédeléc A., Moine B., Rakotondrazafy M. 1994. U$\mathrm{Pb}$, single zircon $\mathrm{Pb}$-evaporation, and $\mathrm{Sm}-\mathrm{Nd}$ isotopic study of a Granulite domain in SE Madagascar. J. Geol., 102:523-538.

Philipp R.P. 1990. Geologia e petroquímica dos granitóides da região de Monte Bonito, Pelotas, RS. Instituto de Geociências, Universidade Federal do Rio Grande do Sul, Porto Alegre, Dissertação de Mestrado, $231 \mathrm{p}$.

Philipp R.P. 1991. Geologia dos granitóides da região de Monte Bonito, Pelotas, RS: uma contribuição ao reconhecimento estratigráfico do Setor Oriental do Escudo Sul-Riograndense. Acta Geol. Leopold., v.XIV, 33:71-128.

Philipp R.P. 1998. A evolução geológica e tectônica do Batólito Pelotas no Rio Grande do Sul. Instituto de Geociências, Universidade de São Paulo, São Paulo, Tese de Doutorado, 255p.

Philipp R.P., Almeida D.P.M., Gomes M.E.B., Pintaúde D.A. 1991. Geoquímica do Granito Bela Vista, Piratini, RS: uma contribuição ao conhecimento do magmatismo alcalino no setor Oriental do Escudo. Acta Geol. Leopold., v.XIV, 34:95-122.

Philipp R.P., Mesquita M..J., Gomes M.E.B., Almeida D.P.M. 1993. Reconhecimento estrutural e geoquímico dos Granitóides Brasilianos da região de Pelotas, RS. Pesquisas, 20:3-13

Philipp R.P. \& Viero A.P. 1995. Interação entre o magmatismo ácido/ básico nas rochas vulcânicas associadas aos granitóides da região de Porto Alegre, RS. In: SBG, Simp. Sul-Bras. Geol., 6, Bol. Res. Expandidos, Porto Alegre, SBG, p.70-71.

Philipp R.P., Nardi L.V.S., Machado R. 1998. O Magmatismo Granítico Neoproterozóico tardi a pós-colisional da região de Porto Alegre, RS. In: Contribuição ao estudo dos granitos e rochas correlatas. SBG, Núcleo Bahia-Sergipe, Pub. Esp., 5, pp.: 129-152.

Philipp R.P., Nardi L.V.S., Bitencourt M.F. 2000. O Batólito Pelotas no Rio Grande do Sul. In: M. Holz \& L.F. De Ros (eds.) Geologia do Rio Grande do Sul. CIGO-UFRGS, Porto Alegre, pp.: 133-160.

Philipp, R.P. \& Machado, R. 2001. Estratigrafia e significado tectônico das suítes graníticas do Batólito Pelotas no Rio Grande do Sul, Brasil. Rev.Bras. Geoc., 31:257-266.

Philipp R.P. \& Machado R. 2002a. Ocorrência e significado dos septos do embasamento encontrados nas Suítes Graníticas do Batólito Pelotas, RS. Pesquisas, UFRGS, (no prelo).

Philipp R.P. \& Machado R. 2002b. The Neoproterozoic to Cambrian granitic magmatism of Pelotas Batholith, southern Brazil. $J$. Sout. Am. Ear: Sci., (no prelo).

Philipp R.P., Nardi L.V.S., Machado R. 2002c. Granitóides peralcalinos pós-colisionais do Batólito Pelotas, sul do Brasil: o Granito Bela Vista. In: SBG, Cong. Bras. Geol,, 38, João Pessoa (submetido).

Plá Cid J., Nardi L.V.S., Stabel L. 2002. K-clinopyroxene and potassian pargasite in mafic microgranular enclaves of Piquirí syenite, southernmost Brazil: evidences of syenitic and lamprophyric magma mingling at high pressure. Contr: Mine. Petrol. (submetido)

Porcher C.C. 1992. Caracterização das condições de fluxo de uma zona de cisalhamento tangencial na região de Santana da Boa Vista $(R S)$. Instituto de Geociências, Universidade Federal do Rio Grande do Sul, Porto Alegre, Dissertação de Mestrado, $192 \mathrm{p}$.

Porcher C.C., McNaughton N.J., Leite J.A.D., Hartmann L.A., Fernandes L.A.D. 2001. Basement-cover relationships in southern Brazil based on SHRIMP zircon ages. Prec. Res. 
(submetido).

Stacey J.S. \& Kramers J.D. 1975. Approximation of terrestrial lead isotope evolution by a two-stage model. Ear. Planet. Sci Lett., 26:207-221

Shukowsky W. \& Mantovani M.S.M. 1991. Estruturação dos terrenos Pré-Cambrianos da região sul do Brasil e oeste do Uruguai: um estudo por modelamento gravimétrico. Revi. Bas. Geoc., 19:275-287.

Silva L.C., Hartmann L.A., McNaughton N.J., Fletcher I.R. 1999. $\mathrm{U}-\mathrm{Pb}$ zircon dating of Neoproterozoic granite magmatism and collision in the Pelotas Batholith, southernmost Brazil. Intern. Geol. Review, 41:531-551.

Soliani Jr. E. 1986. Os dados geocronológicos do Escudo Sul-riograndense e suas implicações de ordem geotectônica, Instituto de Geociências, Universidade de São Paulo, São Paulo, Tese de Doutoramento, 425p.

Stabel L.Z., Nardi L.V.S., Plá Cid J. 2001. Química mineral e evolução petrológica do Sienito Piquiri: magmatismo shoshonítico, neoproterozóico, pós-colisional no sul do Brasil. Rev. Bras. Geoc.(no prelo).

Teixeira W. 1982. Folhas SH.22-Porto Alegre, SI.22 - Lagoa Mirim e SH.2I - Uruguaiana. Interpretação dos dados radiométricos $e$ evolução geocronológica, Florianópolis, Projeto RADAMBRASIL, Relatório Interno.

Tommasi A. 1991. Evolução cinemática do Cinturão Dom Feliciano durante o Ciclo Brasiliano. Instituto de Geociências, Universidade Federal do Rio Grande do Sul, Porto Alegre, Dissertação de Mestrado, 207p.

Vasquez M. L. 1997. Evolução petrogenética dos granitos da Suíte Intrusiva Encruzilhada do Sul-RS. Instituto de Geociências, Universidade Federal do Rio Grande do Sul, Porto Alegre, Dissertação de Mestrado, 195p.

Vieira Jr. N., Fernandes L.A.D., Koester E., Scherer C.S. 1989 Enclaves microgranulares do Maciço de Piquiri-RS. Acta Geol. Leopold., 29(12):185-206

Wildner W. \& Ramgrab G.E. 1994. O Diorito Capim Branco. In SBG, Cong. Bras. Geol., 38, Camboriú, Bol. Res. Expandidos 3:61-62.

Manuscrito A-1272

Recebido em 12 de novembro de 2001

Revisão dos autores em 28 de junho de 2002 Revisão aceita em 30 de junho de 2002 